\title{
Differential expression of the miR-17-92 cluster and miR-17 family in breast cancer according to tumor type; results from the Norwegian Women and Cancer (NOWAC) study
}

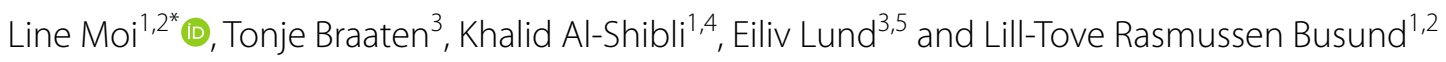

\begin{abstract}
Background: MicroRNAs (miRNAs) are promising biomarkers due to their structural stability and distinct expression profile in various cancers. We wanted to explore the miRNA expression in benign breast tissue and breast cancer subgroups in the Norwegian Women and Cancer study.

Methods: Specimens and histopathological data from study participants in Northern Norway diagnosed with breast cancer, and benign tissue from breast reduction surgery were collected. Main molecular subtypes were based on surrogate markers; luminal A (ER+ and/or PR+, HER2 - and Ki67 $\leq 30 \%$ ), luminal B (ER+ and/or PR+, HER2 - and Ki67 $>30 \%$ or ER + and/or PR + and HER2 +), HER2 positive (ER - and PR - and HER2 +) and triple-negative (ER-, PRand HER2-). RNA was extracted from formalin-fixed paraffin-embedded (FFPE) tissue, and miRNAs were successfully analyzed in 102 cancers and 36 benign controls using the 7th generation miRCURY LNA microarray containing probes targeting all human miRNAs as annotated in miRBASE version 19.0. Validation with RT-qPCR was performed.

Results: On average, 450 miRNAs were detected in each sample, and 304 miRNAs were significantly different between malignant and benign tissue. Subgroup analyses of cancer cases revealed 23 miRNAs significantly different between ER+ and ER - tumors, and 47 miRNAs different between tumors stratified according to grade. Significantly higher levels were found in high grade tumors for miR-17-5p ( $p=0.006)$, miR-20a-5p $(p=0.007)$, miR106b-5p ( $p=0.007)$, miR-93-5p ( $p=0.007)$ and miR-25-3p $(p=0.015)$ from the paralogous clusters miR-17-92 and miR-106b-25. Expression of miR-17-5p ( $p=0.0029)$, miR-20a-5p ( $p=0.0021)$, miR-92a-3p ( $p=0.011)$ and miR-106b-5p $(p=0.021)$ was significantly higher in triple-negative tumors compared to the rest, and miR-17-5p and miR-20a-5p were significantly lower in luminal A tumors.

Conclusions: miRNA expression profiles were significantly different between malignant and benign tissue and between cancer subgroups according to ER - status, grade and molecular subtype. miRNAs in the miR-17-92 cluster and miR-17 family were overexpressed in high grade and triple-negative tumors associated with aggressive behavior. The expression and functional role of these miRNAs should be further studied in breast cancer to explore their potential as biomarkers in diagnostic pathology and clinical oncology.
\end{abstract}

Keywords: Breast cancer, MicroRNA, miR-17-92-cluster, miR-106b-25 cluster, miR-17-family, NOWAC

\footnotetext{
*Correspondence: Line.Moi@unn.no

${ }^{2}$ Department of Clinical Pathology, University Hospital of North Norway,

Tromsø, Norway

Full list of author information is available at the end of the article
} 


\section{Background}

Breast cancer is a leading cause of cancer-related deaths. Annually, approximately 2.09 million women worldwide are diagnosed with breast cancer whereas an estimated 627.000 women die of the disease [1]. Breast cancer incidence has been increasing over the last decades in the Western world, also in Norway [2]. Mortality rates are falling, leaving an increasing number of women alive with a history of the disease, but also exposed to risk of complications and side-effects due to treatment and with a life-long risk of relapse. There is a need for simple, safe and informative diagnostic tools to better identify the breast cancer tumors with the most aggressive behavior and to diagnose and treat the disease before distant metastases have been established and the disease is beyond curability.

MicroRNAs (miRNAs) are short single-stranded RNAs built up of 18-22 nucleotides after processing of the pri-miRNA by the nuclear RNase III protein Drosha and sequentially cleavage of the hairpin-shaped precursor-miRNA by the RNase III Dicer in the cells' cytoplasm [3]. MiRNAs are important regulators of gene expression at the post-transcriptional level, usually by either inhibiting translation or inducing mRNA degradation through incomplete or complete binding to a complementary sequence in the $3^{\prime}$ untranslated region (UTR) of their target mRNAs. It is well established that miRNAs are involved in carcinogenesis, invasion and metastasis $[4,5]$ and display distinct profiles in cancer [6]. Further, miRNAs have properties that make them promising as biomarkers. They can be detected in blood, partly in extracellular vesicles known as exosomes, and in other body fluids such as urine and saliva $[7,8]$. MiRNAs are very stable structures and can tolerate freezing and thawing [9]. Further, if miRNAs in blood could give information on the phenotype or aggressiveness of a given tumor, there is a possibility that easily obtained samples could give information on malignant disease, both at the time of primary diagnosis and in the metastatic setting [10].

The Norwegian Women and Cancer study (NOWAC) is a prospective study which started in 1991 and includes 172,000 Norwegian women aged 30-70 years randomly sampled from the Norwegian Central Person Registry. The study is based on questionnaires with information on variables of importance to breast cancer risk such as lifestyle, use of oral contraceptives, hormone replacement therapy, reproductive history and family history of breast cancer. From 2003 the study was expanded to include blood samples for whole-genome expression profiling (the NOWAC postgenome cohort) [11]. 49,633 samples of peripheral blood have been collected. Through linkage to the Cancer Registry of Norway, women in the
NOWAC postgenome cohort with a diagnosis of breast cancer have been identified.

The aim of this pilot study was to explore the miRNA expression profile in breast cancer tumors from the NOWAC postgenome cohort and to search for miRNAs that are significantly different in tumor tissue compared to benign breast tissue and could be detected in formalinfixed paraffin-embedded (FFPE) tissue, collected as part of routine diagnostics. Further, we wanted to identify miRNAs that are differently expressed in tumors with different aggressiveness and prognosis with special focus on high grad tumors and the triple-negative breast cancers.

\section{Methods}

\section{Patient material and tumor classification}

The 108 patients included in this pilot study were all participants in the NOWAC postgenome cohort living in Northern Norway and diagnosed with breast cancer in the years 2004-2010. Diagnostic biopsies and breast cancer surgery were performed at the University Hospital of North Norway or the Nordland Central Hospital. As benign controls, FFPE tissues from 44 women undergoing breast reduction surgery were included in the study. The controls were born in the same time period as the NOWAC participants (1943-1957) and underwent surgery in the same time period. Archived FFPE tissue blocks were retrieved from the pathology labs at the University Hospital of North Norway and the Nordland Central Hospital together with the corresponding hematoxylin and eosin slides.

Histopathological data such as histological type, grade, size and lymph node status were collected from the original pathology reports, but reevaluated and completed according to updated criteria by the breast pathologist in charge. Tumor grade was assessed based on gland formation, nuclear pleomorphism and mitotic count, based on the criteria modified by Elston and Ellis [12]. Immunohistochemical (IHC) analyses of estrogen receptor (ER), progesterone receptor (PR) and HER2 were performed on the needle biopsies from tumor taken at the time of diagnosis, as part of routine diagnostics. Cut-off value for ER positivity was $\geq 1 \%$ and for $P R \geq 10 \%$. A HER 2 IHC score of $3+$ was considered positive, a score of $0-1+$ negative whereas a score of $2+$ would lead to further assessment of HER2 status by silver in situ hybridization (SISH). HER2 gene amplification was considered present if HER2/chromosome 17-ratio was $>2.2$. IHC staining for the proliferation marker Ki67 was done on histological slides of tumor tissue from the primary surgery to differentiate between luminal A and luminal B tumors. Ki67 expression was evaluated in at least 500 tumor cells in the most proliferative active parts of tumor and reported as the percentage of positive tumor cell nuclei. 
The main molecular breast cancer subtypes were defined based on clinical grouping and immunohistochemical staining of ER, PR, HER2 and Ki67 as recommended by the St Gallen International Expert Consensus and previous publications $[13,14]$ as follows: luminal A (ER+ and/or PR+, HER2 - and Ki67 $\leq 30 \%)$, luminal B (ER+ and/or PR+, HER2- and Ki67 $>30 \%$ or ER+ and/ or $\mathrm{PR}+$ and HER2+), HER2 positive (ER - and PR - and HER2+) and triple-negative (ER-, PR - and HER2-). The term triple-negative cancer was preferred over basallike breast cancer since subgrouping was done as part of clinical, treatment-oriented classification and was based on receptor status alone. Most basal-like cancers are triple-negative, but triple-negative breast cancers are found to be genetically heterogeneous and are generally not considered synonymous with basal-like tumors [15], although considerable overlap has been demonstrated [16].

\section{RNA extraction and microarray procedures}

A trained pathologist selected the most representative tumor areas on histological slides and tissue cores from the corresponding areas of the FFPE blocks were collected for extraction of total RNA using the RecoverAll Total Nucleic Acid Isolation kit (Life Technologies, Grand Island, NY, USA). Exiqon (Vedbaek, Denmark) performed the microarray hybridization and analyses as a bought service. In short, RNA quality and quantity was assessed using the NanoDrop 1000 spectrophotometer (Thermo Fisher Scientific, Wilmington, DE), and $250 \mathrm{ng}$ total RNA from samples and reference was labeled with $\mathrm{Hy}^{\mathrm{TM}}{ }^{\mathrm{M}}$ and $\mathrm{Hy}^{\mathrm{TM}}$ fluorescent label (Exiqon, Vedbaek, Denmark), respectively, using the miRCURY LNA ${ }^{\mathrm{TM}}$ microRNA Hi-Power Labeling Kit (Exiqon, Vedbaek, Denmark). The $\mathrm{Hy} 5^{\mathrm{TM}}$-labeled reference RNA contained an equal aliquot of all RNA species included in the study. The $\mathrm{Hy} 3^{\mathrm{TM}}$-labeled samples and $\mathrm{Hy} 5^{\mathrm{TM}}$-labeled reference RNA were mixed and hybridized to the 7 th generation miRCURY LNA miRNA array (Exiqon) which contains capture probes targeting identified miRNAs in human, mouse, rat and their related viral sequences as annotated in miRBASE. According to Exiqon, the array contained 3100 capture probes covering $94 \%$ of the human miRNAs in miRBASE version 19.0. The hybridization was done using a Tecan HS4800 hybridization station (Tecan, Austria) and the microarray slides were stored in an ozone free environment after hybridization. The slides were scanned using the Agilent G2565BA Microarray Scanner System (Agilent technologies Inc., USA) and the image analysis was carried out using the ImaGene 9.0 software (BioDiscovery Inc., USA). The quantified signals were background corrected and normalized using quantile normalization method. The detection threshold was calculated as 1.2 times the 25th percentile of the overall signal intensity of the individual slides. MiRNAs with intensities above threshold in $<20 \%$ of the samples were removed from the final dataset used for the expression analyses to ensure that the expression analyses were done on miRNAs which were expressed in enough samples to be of biological relevance [17]. However, all miRNAs, independently of the percentage of samples with detectable expression, were included in a screening analysis to explore if any one miRNA was uniquely expressed in any of the tumor subgroups.

\section{RT-qPCR validation}

To validate the microarray miRNA analyses, RT-qPCR was performed by Exiqon on RNA purified from 40 of the tumor samples and 20 of the benign breast tissue controls included in the study. Due to the clinical relevance of the molecular subtypes and the scientific focus on the triple-negative breast cancers, the tumor samples were randomly selected within each molecular subtype so that there would be about ten cases in each subgroup. 15 of the miRNAs from the microarray analysis were selected for validation. PCR-validation was done after the initial statistical analyses on the miRNA expression levels from the microarray had been performed. MiRNAs with highly significant differences between tissue types and/or tumors subgroups according to tumor grade and receptor status with special focus on the triple-negative breast cancers, were selected for validation. Associated miRNAs, such as miRNA clusters, -family or -strands from a common precursor with a coordinated regulation of expression were given priority over individual miRNAs. However, four single miRNAs of potential interest for future studies were also included, based on known biological functions or potential for novel findings, based on the microarray. The following miRNAs were analyzed using PCR: the let-7 family members let-7b-5p and let-7c, the two miR-126-strands miR-126-5p and miR-126-3p, the miR-143-145 cluster members miR-143-3p and miR-145-5p, and the miR-17-92 cluster/miR-17-family members miR-17-5p, miR-20a-5p, miR-92a-3p, miR106b-5p and miR-93-5p. In addition, the well described miR-155-5p and miR-146a-5p were included in the PCRanalyses. Finally, the less known miRNAs miR-3182 and miR-3164 were included in the PCR-analyses for exploratory purposes. The design of the study and a schematic overview of the analyses done is presented in Fig. 1.

In short, the Qiagen miRNeasy FFPE kit was used to extract RNA from FFPE tissue cores according to the manufacturer's instructions (Qiagen, Hilden, Germany). 10 ng RNA was reverse transcriped using the miRCURY LNA Universal RT microRNA PCR, Polyadenylation and cDNA synthesis kit (Exiqon) before PCR-reactions were 


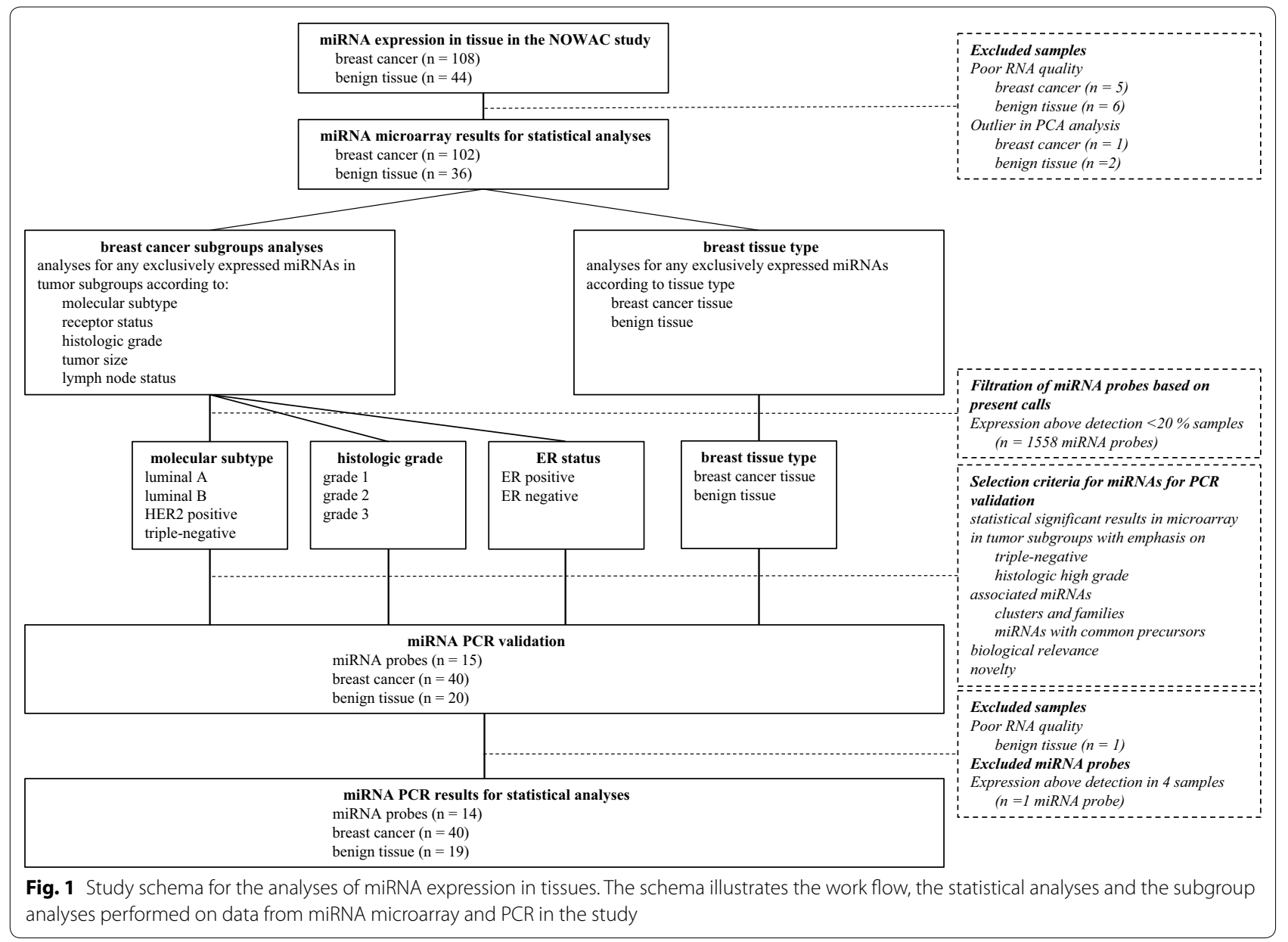

performed on $100 \times$ diluted cDNA using ExiLENT SYBR Green master mix. The amplification was done in 384 well plates in a Light Cycler 480 Real-Time PCR System (Roche, Basel, Switzerland) where all reverse transcription reactions were done in duplicates. The Normfinder software was used by Exiqon to find the most suitable reference miRNAs based on stable expression across the data set. Of the suitable reference miRNAs, miR-664a-3p was detected in all samples in concentrations comparable to the target miRNAs and could be used for normalization. Normalized expression values for each miRNA were calculated based on the PCR quantification cycle (Cq) and the average of the normalizer detected in all samples using the formula: normalized $\mathrm{Cq}=$ average $\mathrm{Cq}$ (all samples) - assay Cq (sample).

\section{Statistics}

The miRNA microarray and PCR expression data were analysed using the Linear Models for Microarray and RNA-Seq Data (Limma) package in R. Moderated F-statistics were applied. $p$-values were corrected for multiple testing by controlling the false discovery rate using the method of Benjamini \& Hochberg. Descriptive statistics, non-parametric tests and correlation analysis, using Pearson correlation, were performed using Stata, version 14 (StataCorp LLC, Texas, USA).

\section{Results}

\section{Patient and tumor characteristics}

The women included in the NOWAC study are all born in the period 1943-1957. The mean age at breast cancer diagnosis in our study was 57.6 years (range 47-65 years) whereas the benign breast tissue controls were collected from women with a mean age at surgery of 57.4 years (range 47-66 years). Of the 108 breast cancer tumors, 81 tumors (75\%) were hormone receptor positive, 20 tumors $(18.5 \%)$ were HER2 positive of which 11 tumors (10.2\%) were triple-positive (ER+, PR+, HER2+), and 16 cases (14.8\%) had triplenegative tumors. 28 of the tumors $(25.9 \%)$ had histologic characteristics of aggressive breast cancer with low differentiation, cellular atypia and high mitotic activity, corresponding to histologic grade 3 . Molecular subclassification of tumors, based on surrogate 
markers, demonstrated 80 tumors $(74.1 \%)$ to be of the luminal type, whereas 9 (8.3\%) and 16 tumors (14.8\%) ended up as HER2 positive and triple-negative, respectively. The patient material and tumor characteristics are presented in Table 1.
MiRNA expression levels in malignant versus normal breast tissue

Of a total of 108 cases of invasive breast cancer cases in this pilot study, five specimens did not have satisfactory RNA quality and were not included in the microarray, and one specimen was identified as an extreme outlier in the unsupervised analyses of the miRNA results using

Table 1 Patient characteristics and clinicopathological variables for the study population and samples included in PCR validation

\begin{tabular}{|c|c|c|c|c|}
\hline \multirow[t]{3}{*}{ Characteristic } & \multicolumn{4}{|c|}{ NOWAC pilot study } \\
\hline & \multicolumn{2}{|c|}{ Study population } & \multicolumn{2}{|c|}{ PCR analyses } \\
\hline & Cases N (\%) & Controls N (\%) & Cases N (\%) & Controls N (\%) \\
\hline Study subjects & $108(100)$ & $44(100)$ & $40(100)$ & $20(100)$ \\
\hline \multicolumn{5}{|l|}{ Age (years) } \\
\hline$\leq 50$ & $7(6.5)$ & $1(2.3)$ & $1(2.5)$ & $1(5.0)$ \\
\hline$>50$ & $101(93.5)$ & $43(97.7)$ & $39(97.5)$ & $19(95.0)$ \\
\hline \multicolumn{5}{|l|}{ Tumor grade } \\
\hline 1 & $34(31.5)$ & - & $7(17.5)$ & - \\
\hline 2 & $42(38.9)$ & - & $17(42.5)$ & - \\
\hline 3 & $28(25.9)$ & - & $16(40.0)$ & - \\
\hline Unknown & $4(3.7)$ & & $0(0)$ & \\
\hline \multicolumn{5}{|l|}{ Tumor size (mm) } \\
\hline $0-10$ & $23(21.3)$ & - & $2(5.0)$ & - \\
\hline $10-20$ & $50(46.3)$ & - & $24(60.0)$ & - \\
\hline$>20$ & $34(31.5)$ & - & $14(35.0)$ & - \\
\hline Unknown & $1(0.9)$ & & $0(0)$ & \\
\hline \multicolumn{5}{|l|}{ Lymph node status } \\
\hline NO & $73(67.6)$ & - & $30(75.0)$ & - \\
\hline $\mathrm{N}+$ & $34(31.5)$ & - & $10(25.0)$ & - \\
\hline Unknown & $1(0.9)$ & - & $0(0)$ & - \\
\hline \multicolumn{5}{|l|}{ Hormone receptor status } \\
\hline ER/PR positive & $81(75.0)$ & - & $23(57.5)$ & - \\
\hline ER/PR negative & $27(25.0)$ & - & $17(42.5)$ & - \\
\hline Unknown & $0(0)$ & - & $0(0)$ & - \\
\hline \multicolumn{5}{|l|}{ HER2 receptor status } \\
\hline HER2 positive & $20(18.5)$ & - & $15(37.5)$ & - \\
\hline HER2 negative & $86(79.6)$ & - & $25(62.5)$ & - \\
\hline Unknown & $2(1.9)$ & - & $0(0)$ & - \\
\hline \multicolumn{5}{|l|}{ Molecular subtype } \\
\hline Luminal A & $58(53.7)$ & - & $12(30.0)$ & - \\
\hline Luminal B & $22(20.4)$ & - & $11(27.5)$ & - \\
\hline HER2 positive & $9(8.3)$ & - & $7(17.5)$ & - \\
\hline Triple-negative & $16(14.8)$ & - & $10(25.0)$ & - \\
\hline Unknown & $3(2.8)$ & & $0(0)$ & \\
\hline \multicolumn{5}{|l|}{ Histological type } \\
\hline Infiltrating carcinoma NST & $92(85.2)$ & - & $35(87.5)$ & - \\
\hline Lobular carcinoma & $10(9.3)$ & - & $3(7.5)$ & - \\
\hline Tubular & $3(2.8)$ & - & $0(0)$ & - \\
\hline Other & $3(2.8)$ & - & $2(5.0)$ & - \\
\hline
\end{tabular}


principal component analysis (PCA), leaving 102 breast cancer specimens for final analysis. Six of the 44 benign breast surgery specimens had RNA quality of unsatisfactory quality and two benign tissue controls were identified as outliers after unsupervised microarray analysis, resulting in 36 benign tissue controls in the final statistical analyses.

Screening analyses of all detected probes did not demonstrate any miRNAs that were uniquely expressed in any of the tissue types or breast cancer subgroups. For further expression analyses, 1558 probes were discarded due to intensities above threshold in less than $20 \%$ of the samples. Noteworthy, the samples contained similar levels of detectable miRNAs indicating comparable sample quality. On average, 450 different miRNAs were detected above threshold in each sample. 304 miRNAs demonstrated significantly different expression levels in tumor tissue compared to normal tissue. Heat map and PCA demonstrated that the miRNAs in normal tissue and tumor samples clustered according to their biological group (Fig. 2). This indicates that differences between the groups are the largest contributors to variation in miRNA expression and underlines that the miRNA profile in malignant and benign breast tissue is significantly different.

Scatterplots of the 20 most significantly differently expressed miRNAs in malignant breast tumors compared to benign breast tissue, based on p-values, are shown in Fig. 3. Noteworthy, of these 20 miRNAs, 18 miRNAs were downregulated in cancer compared to benign breast tissue.

Further, the calculated $\log$ fold change $(\log \mathrm{FC})$ between malignant and benign tissue adds information on the probable biological relevance of the observed difference in miRNA expression. The 20 most upregulated and the 20 most downregulated miRNAs in cancer, based on the $\log \mathrm{FC}$-values, are listed in Table 2.

\section{MiRNA expression levels according to breast cancer subtypes}

The expression of miRNAs in breast cancer stratified according to receptor expression, histologic grade, molecular subtype, tumor size and lymph node status was explored, using moderated F-statistics and the Benjamini \& Hochberg correction for multiple comparisons on microarray miRNA expression data. The analysis revealed that 23 of the detected miRNAs were significantly different between ER+ and ER- tumors (Table 3 and Fig. 4).

A total of 47 miRNAs demonstrated significantly different expression between tumors stratified according to histologic grade. Noteworthy, among the six miRNAs with the most significantly different expression according to grade, two miRNAs in the miR-17-92 cluster and two miRNAs in the paralogue miR-106b-25 cluster were represented: miR-17-5p $(p=0.006)$, miR-20a-5p $(p=0.007)$, miR-106b-5p $(\mathrm{p}=0.007)$, and miR-93-5p $(\mathrm{p}=0.007)$. Also the cluster members miR-25-3p and miR-92a-3p demonstrated significantly different expression according to grade. Subgroup analyses with contrast tests demonstrated that all of these miRNAs in the miR-17-92 and miR-106b-25 clusters were significantly higher expressed in high grade tumors (Table 4 and Fig. 5a, b).

The statistical results when analyzing miRNA expression in high grade tumors, indicated that the miR-1792 and miR-106b-25 clusters were highly interesting. Further, the triple-negative tumors are of special clinical interest due to their aggressive behavior and lack of specific, targeted treatment. When comparing miRNA expression in these tumors compared to the rest, the expression of miR-17-5p $\quad(p=0.0029), \quad m i R-20 a-5 p$ $(\mathrm{p}=0.0021)$, miR-92a-3p $(\mathrm{p}=0.011)$ and miR-106b-5p $(\mathrm{p}=0.021)$ was significantly higher in triple-negative breast cancers (Table 5).

Further, overall and contrast tests comparing the miRNA levels in individual molecular subgroups with correction for multiple comparisons were performed. We found that miR-17-5p and miR-20a-5p were significantly different between luminal $\mathrm{A}$ and triple-negative tumors ( $p=0.001$ for both miRNAs), borderline significant between luminal A and luminal B cancers for both miR-17-5p and miR-20a-5p with FDR-adjusted p-values of 0.06 and 0.07 , respectively, but not between any of the other molecular subgroups or for any of the other miRNAs in the miR-17-92 and miR-106b-5p clusters (Fig. 6). Further, both miR-17-5p $(\mathrm{p}=0.0030)$ and miR-20a-5p $(p=0.0029)$ were lower in luminal A tumors compared to the rest.

The expression of 209 miRNAs was significantly different in tumors according to size, using $20 \mathrm{~mm}$ in diameter

\footnotetext{
(See figure on next page.)

Fig. 2 Heat map and principal component analysis of miRNAs with greatest variability between cases and controls. a Heat map diagram with unsupervised hierarchical clustering is presented for all samples and the top 50 miRNAs with the largest variation across all samples. Each row represents a miRNA and each column represents a sample. The color scale illustrates the relative expression level of a miRNA across all samples: red color represents an expression level below the mean, green color expression above the mean. $\mathbf{b}$ Plot of the principal component analysis performed on all samples and on the 50 miRNAs with the largest variation across all samples. The normalized log-transformed Hy 3 values have been used for the analysis
} 


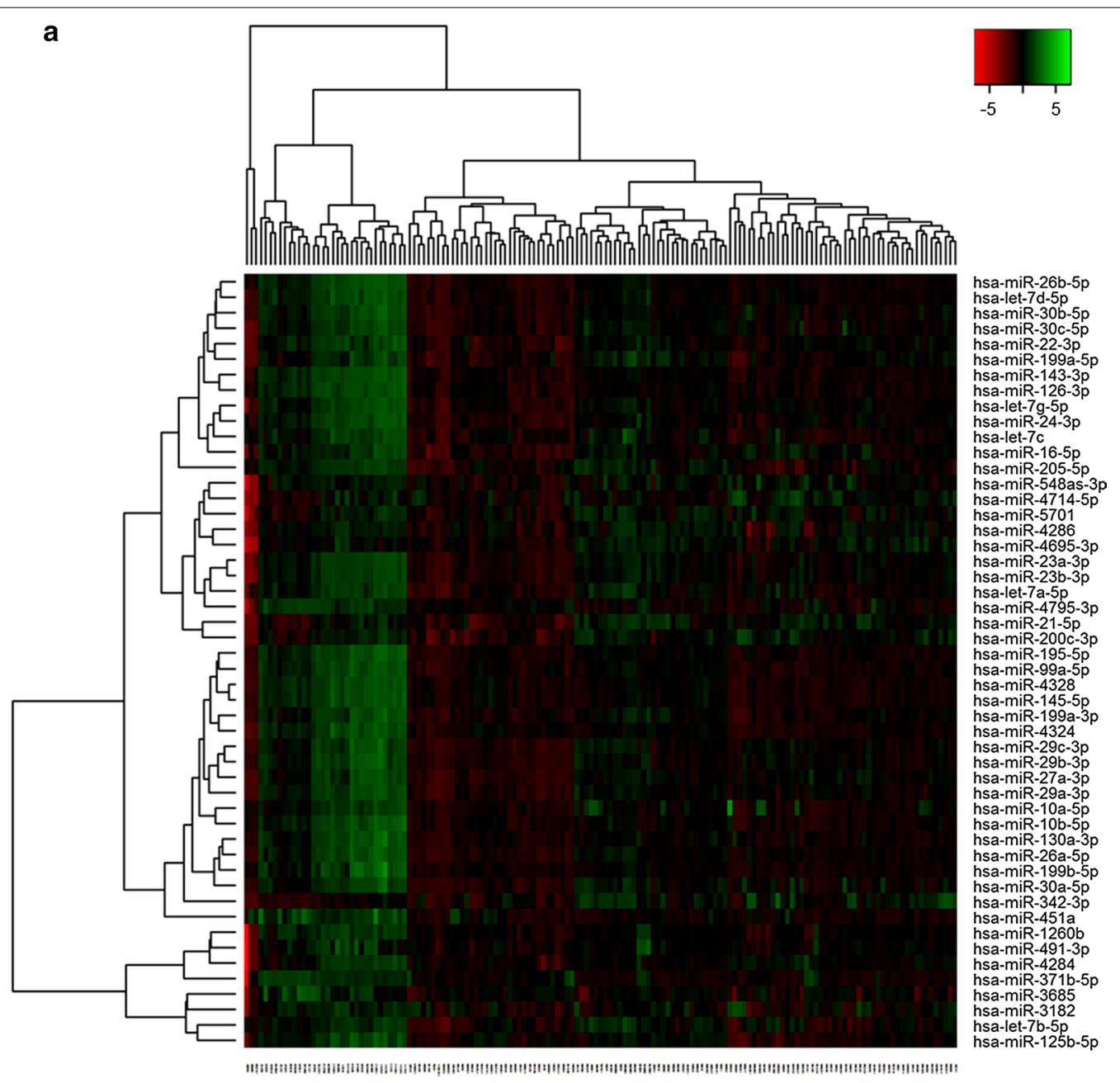

b

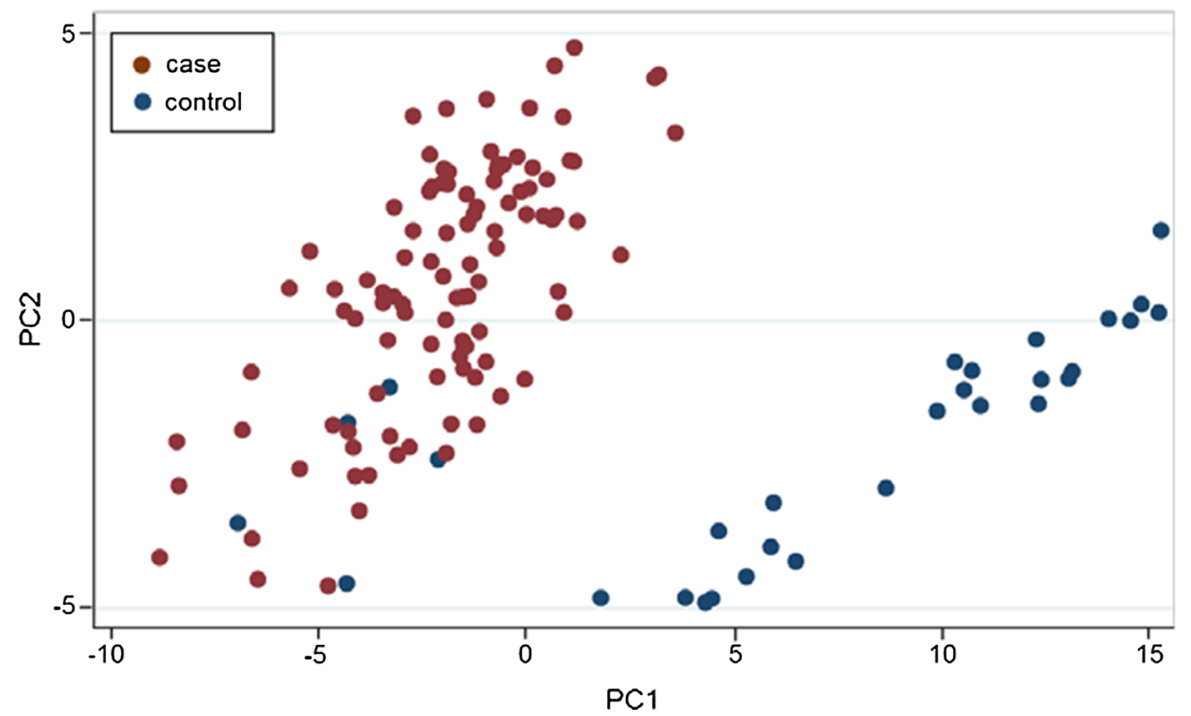




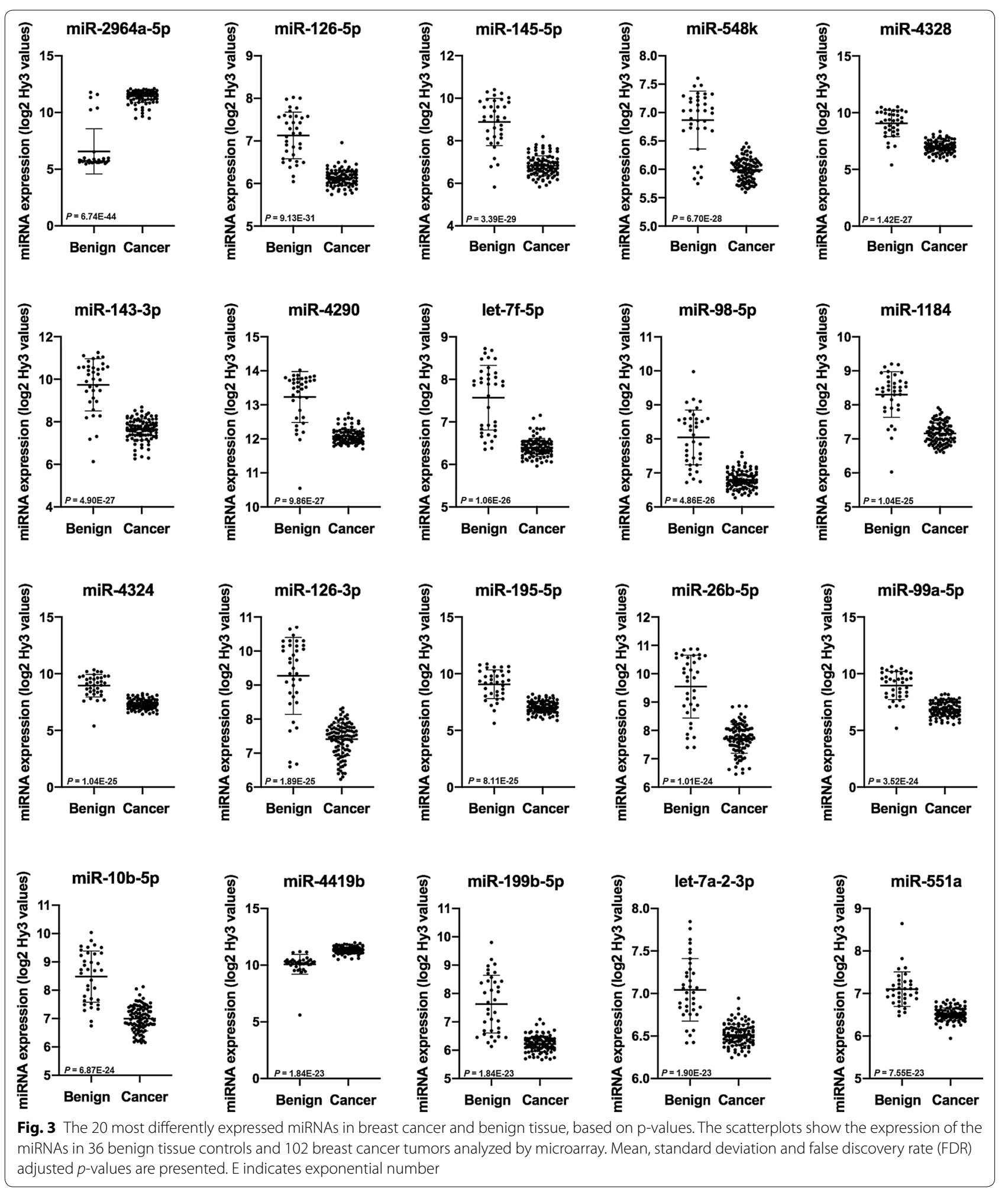


Table 2 The most up- and downregulated miRNAs in cancer compared to benign tissue, sorted by logFC

\begin{tabular}{|c|c|c|}
\hline MiRNA & $\begin{array}{l}\text { LogFC cancer } \\
\text { versus benign }\end{array}$ & $p^{*}$ \\
\hline miR-2964a-5p & 4.859 & $6.74 \mathrm{E}-44$ \\
\hline miR-4419b & 1.249 & $1.84 \mathrm{E}-23$ \\
\hline miR-3164 & 1.146 & $2.22 \mathrm{E}-12$ \\
\hline miR-K12-5-5p & 1.143 & $2.90 E-12$ \\
\hline miR-221-5p & 0.924 & $1.51 \mathrm{E}-17$ \\
\hline miR-585 & 0.920 & $1.80 \mathrm{E}-11$ \\
\hline miR-342-3p & 0.865 & $1.07 \mathrm{E}-07$ \\
\hline miR-766-5p & 0.846 & $1.77 \mathrm{E}-10$ \\
\hline miR-4478 & 0.828 & $1.03 E-21$ \\
\hline miR-338-5p & 0.815 & $2.64 \mathrm{E}-12$ \\
\hline$m i R-21-5 p$ & 0.703 & $8.74 \mathrm{E}-04$ \\
\hline$m i R-342-5 p$ & 0.667 & $3.27 \mathrm{E}-13$ \\
\hline miR-149-3p & 0.660 & $1.46 \mathrm{E}-08$ \\
\hline miR-5196-3p & 0.650 & $6.37 \mathrm{E}-20$ \\
\hline miR-182-5p & 0.644 & $9.59 \mathrm{E}-08$ \\
\hline miR-4644 & 0.592 & $8.30 \mathrm{E}-08$ \\
\hline miR-224-3p & 0.588 & $2.81 \mathrm{E}-11$ \\
\hline miR-4768-5p & 0.586 & $2.13 \mathrm{E}-12$ \\
\hline miR-4778-3p & 0.565 & $5.08 \mathrm{E}-17$ \\
\hline miR-4417 & 0.559 & $5.72 \mathrm{E}-05$ \\
\hline miR-451a & -2.647 & $1.89 \mathrm{E}-18$ \\
\hline miR-143-3p & -2.096 & $4.90 E-27$ \\
\hline miR-99a-5p & -2.093 & $3.52 E-24$ \\
\hline miR-4328 & -2.090 & $1.42 \mathrm{E}-27$ \\
\hline miR-145-5p & -2.061 & $3.39 E-29$ \\
\hline miR-205-5p & -2.027 & $1.45 \mathrm{E}-12$ \\
\hline miR-195-5p & -2.023 & $8.11 \mathrm{E}-25$ \\
\hline miR-125b-5p & -1.970 & $8.70 E-14$ \\
\hline miR-126-3p & -1.862 & $1.89 \mathrm{E}-25$ \\
\hline$m i R-26 b-5 p$ & -1.837 & $1.01 \mathrm{E}-24$ \\
\hline miR-4324 & -1.651 & $1.04 \mathrm{E}-25$ \\
\hline miR-29a-3p & -1.592 & $3.44 \mathrm{E}-12$ \\
\hline miR-10b-5p & -1.483 & $6.87 E-24$ \\
\hline miR-30b-5p & -1.452 & $1.03 E-15$ \\
\hline let-7d-5p & -1.450 & $6.25 \mathrm{E}-21$ \\
\hline miR-130a-3p & -1.406 & $4.80 E-19$ \\
\hline miR-199b-5p & -1.400 & $1.84 \mathrm{E}-23$ \\
\hline miR-29b-3p & -1.339 & $1.56 \mathrm{E}-14$ \\
\hline miR-199a-3p & -1.316 & $2.13 E-13$ \\
\hline miR-24-3p & -1.287 & $7.37 \mathrm{E}-18$ \\
\hline
\end{tabular}

Log fold change (log $\mathrm{FC}$ ) values are calculated, based on the log2 transformed intensity values (Hy3) by microarray analyses, comparing breast cancer to benign tissue controls. The 20 most upregulated and the 20 most downregulated miRNAs, sorted by highest and lowest logFC, respectively, are presented

* False discovery rate (FDR) adjusted $p$-value. E indicates exponential number as cutoff (Additional file 1: Table S1). Finally, there were no significant differences in expression of any miRNA in tumors stratified according to HER2 status or lymph node metastasis.

\section{PCR validation}

14 of the 15 miRNAs selected for PCR validation were successfully quantitated in FFPE tissue, using qPCR (Fig. 7 and Table 6). The previously functionally undescribed miR-3164 was significantly differently expressed in benign versus malignant breast tissue using microarray. However, miR-3164 was only detectable and in very low expression levels in four tumor samples by PCR, which could be due to very low expression levels or suboptimal probes, and was therefore not included in further analyses.

PCR analyses validated the results from the microarray experiment. Let-7b-5p, miR-146a-5p, miR-3182, let-7c and miR-155-5p were among the miRNAs demonstrating significantly different expression according to ER status in the microarray. Comparison between ER positive and ER negative cancers as measured by PCR, validated the results, demonstrating a $\operatorname{logFC}$ of 0.87 for let-7b-5p $(\mathrm{p}=0.029), \log \mathrm{FC}-1.57$ for miR-146a-5p $(\mathrm{p}=0.00014)$, $\operatorname{logFC}-0.99$ for miR-3182 $(\mathrm{p}=0.028), \log \mathrm{FC} 0.88$ for let-7c $(\mathrm{p}=0.029)$ and a $\log \mathrm{FC}$ of -1.64 for miR-155-5p $(p=0.00012)$. Higher levels of the miR-17-92 cluster members were detected in high grade tumors with significant difference between miR-17-5p expression in grade 1 and grade 3 tumors (Fig. 5c). As for microarray, PCRanalyses found significantly higher levels of miR-17-5p $(\mathrm{p}=0.0025)$, miR-20a-5p $(\mathrm{p}=0.0053)$ and miR-92a-3p $(\mathrm{p}=0.0073)$ in triple-negative breast cancers compared to the rest, and the miRNA expression levels tended to be lower in luminal A tumors compared to others, although the adjusted p-values were not significant (Table 7). Importantly, Pearson correlation coefficient demonstrated strong and significant correlations between the microarray and qPCR data for all the 14 detectable miRNAs. Scatterplots comparing microarray and PCR expression levels for the analyzed miR-17-92 and miR106b-25 cluster members are presented in Fig. 8.

\section{Discussion}

This study has explored the miRNA expression profile in breast cancer in the NOWAC study. The distribution of tumor characteristics such as receptor status, histologic grade and molecular subtype is as expected based on findings in larger epidemiological studies and the collected national data in the Norwegian Cancer Registry, again underlining that the NOWAC study population is a representative cohort of the Norwegian female population in this age-group [18]. 
Table 3 MiRNAs demonstrating significantly different expression according to estrogen receptor status

\begin{tabular}{|c|c|c|c|c|c|c|}
\hline \multirow[t]{2}{*}{ miRNA } & \multicolumn{2}{|c|}{ ER positive breast cancer } & \multicolumn{2}{|c|}{ ER negative breast cancer } & \multirow[t]{2}{*}{$\log \mathrm{FC}$} & \multirow[t]{2}{*}{$p^{*}$} \\
\hline & Mean & SD & Mean & SD & & \\
\hline miR-342-3p & 7.60 & 0.79 & 6.72 & 0.51 & 0.881 & $2.29 \mathrm{E}-4$ \\
\hline let-7b-5p & 10.36 & 0.79 & 9.48 & 0.64 & 0.878 & $2.76 \mathrm{E}-4$ \\
\hline miR-125a-3p & 9.01 & 0.46 & 8.50 & 0.42 & 0.514 & $2.76 \mathrm{E}-4$ \\
\hline miR-146a-5p & 6.04 & 0.40 & 6.60 & 0.74 & -0.561 & $5.16 \mathrm{E}-4$ \\
\hline miR-3182 & 9.74 & 0.82 & 10.64 & 0.92 & -0.900 & $7.20 \mathrm{E}-4$ \\
\hline miR-146b-5p & 6.59 & 0.36 & 7.03 & 0.56 & -0.442 & $9.16 \mathrm{E}-4$ \\
\hline miR-222-3p & 6.97 & 0.40 & 7.43 & 0.63 & -0.464 & 0.0021 \\
\hline miR-142-3p & 6.85 & 0.48 & 7.39 & 0.76 & -0.540 & 0.0030 \\
\hline let-7c & 8.36 & 0.67 & 7.79 & 0.41 & 0.564 & 0.0045 \\
\hline miR-342-5p & 6.67 & 0.42 & 6.30 & 0.33 & 0.365 & 0.0048 \\
\hline miR-155-5p & 7.28 & 0.24 & 7.53 & 0.40 & -0.251 & 0.011 \\
\hline miR-let-7a-5p & 9.28 & 0.79 & 8.68 & 0.49 & 0.595 & 0.017 \\
\hline miR-920 & 7.05 & 0.22 & 7.22 & 0.19 & -0.171 & 0.018 \\
\hline miR-214-3p & 8.33 & 0.42 & 8.00 & 0.41 & 0.337 & 0.018 \\
\hline miR-223-5p & 6.35 & 0.38 & 6.68 & 0.50 & -0.332 & 0.020 \\
\hline miR-574-3p & 7.50 & 0.19 & 7.34 & 0.21 & 0.154 & 0.027 \\
\hline miR-3135a & 6.42 & 0.14 & 6.54 & 0.22 & -0.126 & 0.033 \\
\hline miR-20a-5p & 6.58 & 0.42 & 7.00 & 0.86 & -0.420 & 0.040 \\
\hline miR-221-3p & 6.64 & 0.26 & 6.87 & 0.41 & -0.223 & 0.042 \\
\hline miR-665 & 9.15 & 0.52 & 9.56 & 0.68 & -0.410 & 0.042 \\
\hline miR-4758-3p & 6.60 & 0.29 & 6.81 & 0.28 & -0.205 & 0.044 \\
\hline miR-4419b & 11.28 & 0.28 & 11.47 & 0.24 & -0.195 & 0.044 \\
\hline miR-4436b-3p & 6.85 & 0.32 & 7.07 & 0.26 & -0.219 & 0.044 \\
\hline
\end{tabular}

Expression levels are given as the mean with standard deviation (SD) of log2 transformed intensity values (Hy3) by microarray analyses

* False discovery rate (FDR) adjusted $p$-value. E indicates exponential number

Noteworthy, we found the miRNA expression profile to be significantly different in benign and malignant breast tissue, as illustrated by the principal component analysis. Of the 20 most differentially expressed miRNAs in microarray, presented in Fig. 3, only two miRNAs demonstrated higher expression levels whereas 18 miRNAs demonstrated lower expression levels in tumor compared to benign breast tissue. Of 14 miRNAs quantitated by PCR, 12 miRNAs were significantly differently expressed in breast cancer and benign tissue, of which seven miRNAs had significantly lower expression in breast cancer tissue. Tumors have often been found to have reduced levels of mature miRNA which could be explained by defects in their biogenesis, for instance through loss of key proteins in their synthesis such as DICER, epigenetic silencing through mechanisms such as promoter hypermethylation and/or genetic loss of miRNA loci $[5,19]$.

Among the most differentially expressed miRNAs, we found downregulation in tumor tissue of miRNAs such as miR-143-3p and miR-145-5p in the miR143/145 cluster, miR-10b-5p, miR-99a and let-7a-2-3p which is in line with other studies comparing malignant and benign breast tissue [20-25]. Among the 20 most deregulated miRNAs, we observed significantly higher levels of miR-4419b and miR-2964a-5p. MiR-4419b has been found to be upregulated in small cell tumors of the esophagus with rapid relapse after surgery [26] and miR-2964a in pancreatobiliary adenocarcinoma [27], but they are not functionally described in breast cancer. However, as established by miRNA profiling across cancer types, many of the deregulated miRNAs are common in different malignancies.

Analyses of the breast cancer cases revealed significant differences between cancer subtypes. ER is of special interest in breast cancer as a prognostic and predictive marker, and we found 23 miRNAs to be significantly different according to ER status. Among these, miR-155 has previously been shown to be upregulated in breast cancer compared to normal tissue and upregulated in ER- compared to ER+ tumors [22, 24, 28 ], as verified in our study. Noteworthy, miR-342-3p, which we found to be most significantly different with higher expression in ER+ compared to ER - tumors, has also been found by others to be strongly associated 


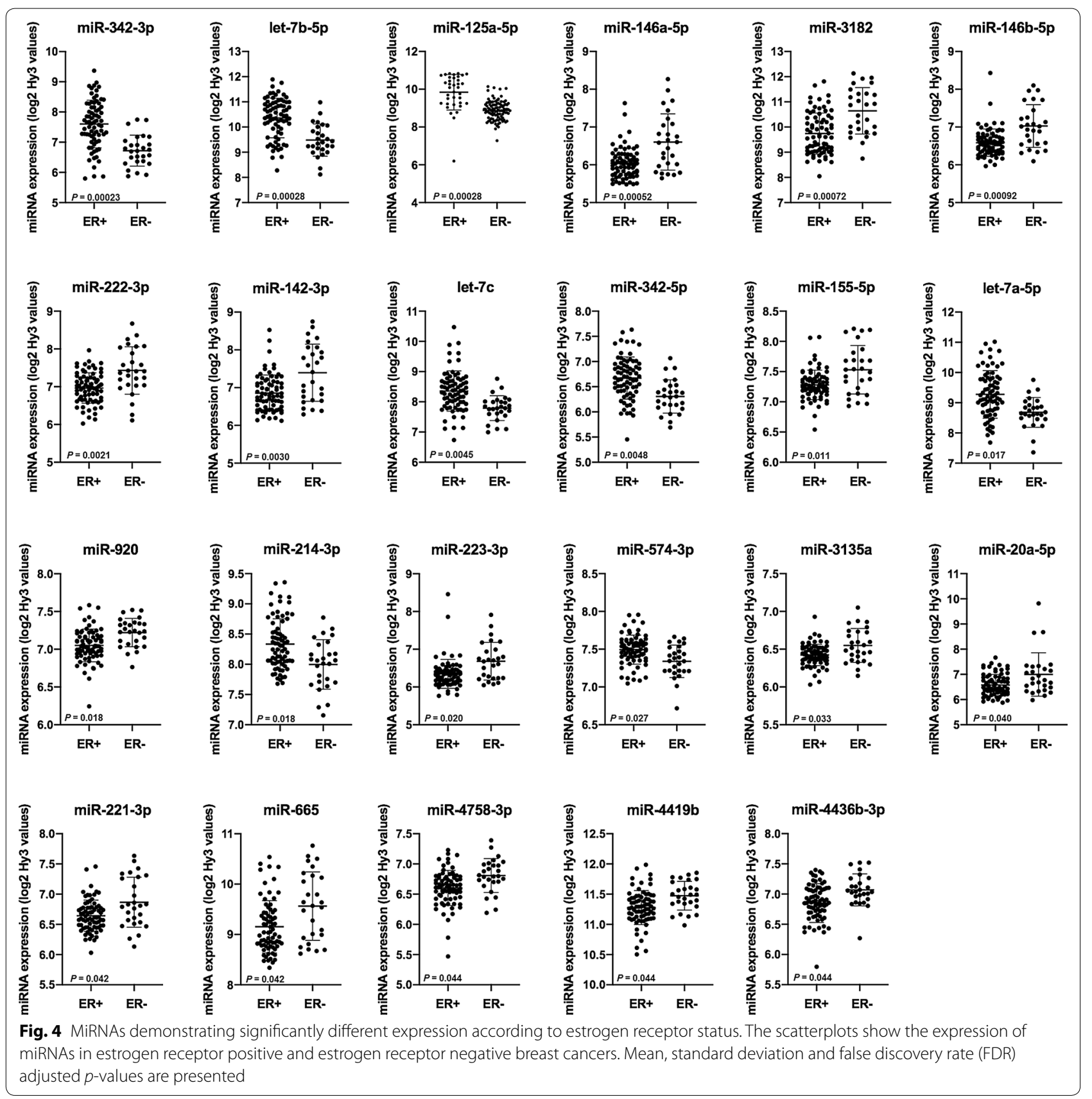

with ER+ status and to predict ER+ receptor status $[29,30]$.

Interestingly, when using an agnostic approach and exploring the miRNA expression profile in breast cancer tissue in an epidemiological study using microarray, four of the six miRNAs found to be most significantly different between tumors of different grade, were miR-17-5p, miR-20a-5p, miR-106b-5p and miR-93-5p, belonging to the miR-17-92 cluster and its paralogue miR-106b-25, and all members of the miR-17 family. Further analyses demonstrated that these miRNAs were significantly higher in tumors with high histologic grade and triplenegative status. Other studies have also found higher levels of miRNAs in these clusters in the most aggressive breast cancers using fresh-frozen tumor tissue and a bead-based flow cytometric miRNA expression method, analyzing on a smaller number of miRNAs than in our study [28]. Calvano Filho et al. found higher levels of miRNAs in the miR-17-92 cluster and miR-17 family in selected triple-negative tumors compared to luminal A 
Table 4 Expression of miRNAs in the miR-17-92 and miR-106b-25 clusters according to histologic grade

\begin{tabular}{|c|c|c|c|c|c|c|}
\hline MiRNA & Tissue & Grade & $\mathbf{n}$ & Mean (SD) & Contrasts & $p^{*}$ \\
\hline \multirow[t]{5}{*}{ miR-17-5p } & Benign & - & 36 & $6.67(0.68)$ & & \\
\hline & Cancer & All & 102 & $6.32(0.66)$ & Cancer vs benign & 0.014 \\
\hline & Cancer & 1 & 32 & $6.10(0.45)$ & Grade 1 vs 2 and 3 & 0.0040 \\
\hline & Cancer & 2 & 41 & $6.16(0.48)$ & Grade 1 and 2 vs 3 & $2.45 E-5$ \\
\hline & Cancer & 3 & 27 & $6.82(0.85)$ & Grade 1 vs 3 & $6.84 \mathrm{E}-5$ \\
\hline \multirow[t]{5}{*}{ miR-20a-5p } & Benign & - & 36 & $7.34(0.74)$ & & \\
\hline & Cancer & All & 102 & $6.69(0.60)$ & Cancer vs benign & $1.23 \mathrm{E}-6$ \\
\hline & Cancer & 1 & 32 & $6.54(0.38)$ & Grade 1 vs 2 and 3 & 0.014 \\
\hline & Cancer & 2 & 41 & $6.52(0.39)$ & Grade 1 and 2 vs 3 & $2.45 \mathrm{E}-5$ \\
\hline & Cancer & 3 & 27 & $7.14(0.82)$ & Grade 1 vs 3 & $8.50 \mathrm{E}-5$ \\
\hline \multirow[t]{5}{*}{ miR-92a-3p } & Benign & - & 36 & $7.79(0.62)$ & & \\
\hline & Cancer & All & 102 & $7.23(0.52)$ & Cancer vs benign & $1.23 \mathrm{E}-6$ \\
\hline & Cancer & 1 & 32 & $7.19(0.47)$ & Grade 1 vs 2 and 3 & 0.27 \\
\hline & Cancer & 2 & 41 & $7.06(0.42)$ & Grade 1 and 2 vs 3 & 0.00037 \\
\hline & Cancer & 3 & 27 & $7.55(0.59)$ & Grade 1 vs 3 & 0.0068 \\
\hline \multirow[t]{5}{*}{ miR-106b-5p } & Benign & - & 36 & $6.68(0.59)$ & & \\
\hline & Cancer & All & 102 & $6.56(0.51)$ & Cancer vs benign & 0.24 \\
\hline & Cancer & 1 & 32 & $6.36(0.38)$ & Grade 1 vs 2 and 3 & 0.0019 \\
\hline & Cancer & 2 & 41 & $6.49(0.44)$ & Grade 1 and 2 vs 3 & $6.84 \mathrm{E}-5$ \\
\hline & Cancer & 3 & 27 & $6.91(0.61)$ & Grade 1 vs 3 & $6.84 \mathrm{E}-5$ \\
\hline \multirow[t]{5}{*}{ miR-93-5p } & Benign & - & 36 & $6.81(0.41)$ & & \\
\hline & Cancer & All & 102 & $7.00(0.56)$ & Cancer vs benign & 0.095 \\
\hline & Cancer & 1 & 32 & $6.80(0.39)$ & Grade 1 vs 2 and 3 & 0.0032 \\
\hline & Cancer & 2 & 41 & $6.92(0.47)$ & Grade 1 and 2 vs 3 & $6.84 \mathrm{E}-5$ \\
\hline & Cancer & 3 & 27 & $7.39(0.69)$ & Grade 1 vs 3 & $8.50 E-5$ \\
\hline \multirow[t]{5}{*}{ miR-25-3p } & Benign & - & 36 & $6.63(0.33)$ & & \\
\hline & Cancer & All & 102 & $6.54(0.33)$ & Cancer vs benign & 0.19 \\
\hline & Cancer & 1 & 32 & $6.44(0.23)$ & Grade 1 vs 2 and 3 & 0.013 \\
\hline & Cancer & 2 & 41 & $6.48(0.28)$ & Grade 1 and 2 vs 3 & 0.00016 \\
\hline & Cancer & 3 & 27 & $6.75(0.41)$ & Grade 1 vs 3 & 0.00043 \\
\hline
\end{tabular}

Expression levels are given as the mean (standard deviation) of log2 transformed intensity values (Hy3) by microarray analyses

* False discovery rate (FDR) adjusted $p$-value. E indicates exponential number

breast cancers, using RT-PCR [31]. MiR-18a and $-18 \mathrm{~b}$ have been shown to have higher expression levels in ERcompared to ER+ tumors, and to directly target ER $\alpha$ [32].

Of note, when comparing the clustered miRNAs' expression in breast cancer to benign tissue, we found significantly higher expression of miR-106b-5p and miR93-5p in breast cancer tissue compared to benign tissue using PCR; by using microarray we found no significant differences. Higher levels of miR-17 family members such as miR-93, miR-25 and miR-106b in cancer have also been demonstrated in other studies using deep sequencing, microarray and/or PCR [33-35]. Several of these studies were smaller than ours and used tissue adjacent to the breast tumor as benign tissue controls. As in our study, using microarray, others have also found members of the miR-17-92 cluster and miR-17 family such as miR17-5p, miR-20a-5p and miR-92a-3p to be downregulated in solid cancers compared to benign tissue [19, 24]. We could, however, only validate this result for miR-92a-3p using PCR; for miR-17-5p and miR-20a-5p no significant difference was observed. Noteworthy, in the PCR-assays, a relative larger proportion of the cancers was triplenegative compared to the entire study cohort included in the microarray, underlining that differences between breast cancer subgroups could influence comparisons between cancer and benign tissue. Although our study includes more tumor and benign tissue samples compared to many other studies, our study material is still small, and the results must be interpreted with caution. Further, when performing expression analyses on tissue, 


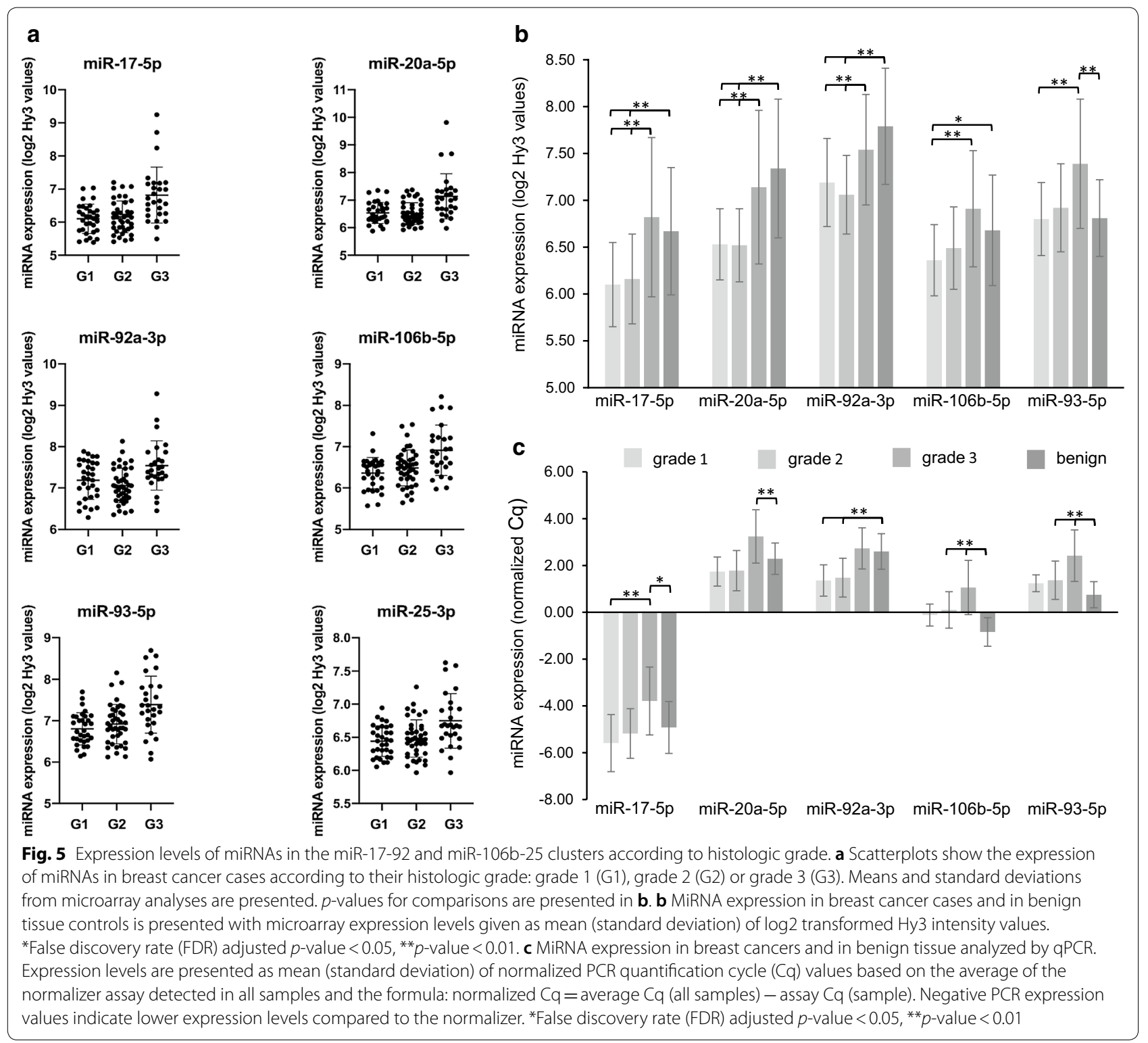

Table 5 Expression of the miR-17-92 cluster and paralogues in triple-negative tumors compared to others, using microarray

\begin{tabular}{|c|c|c|c|c|c|c|}
\hline \multirow[t]{2}{*}{ MiRNA } & \multicolumn{2}{|c|}{ Triple-negative tumors } & \multicolumn{2}{|c|}{ Not triple-negative tumors } & \multirow[t]{2}{*}{$\log \mathrm{FC}$} & \multirow[t]{2}{*}{$p^{*}$} \\
\hline & Mean & SD & Mean & SD & & \\
\hline miR-17-5p & 6.80 & 1.10 & 6.22 & 0.50 & 0.581 & 0.0029 \\
\hline miR-20a-5p & 7.16 & 1.05 & 6.60 & 0.42 & 0.566 & 0.0021 \\
\hline miR-92a-3p & 7.55 & 0.75 & 7.17 & 0.44 & 0.384 & 0.011 \\
\hline miR-106b-5p & 6.84 & 0.72 & 6.50 & 0.45 & 0.341 & 0.021 \\
\hline miR-93-5p & 7.23 & 0.76 & 6.96 & 0.51 & 0.270 & 0.094 \\
\hline miR-25-3p & 6.66 & 0.41 & 6.51 & 0.31 & 0.147 & 0.10 \\
\hline
\end{tabular}

Expression levels are given as the mean (standard deviation) of log2 transformed intensity values (Hy3) by microarray analyses

* False discovery rate (FDR) adjusted $p$-value 


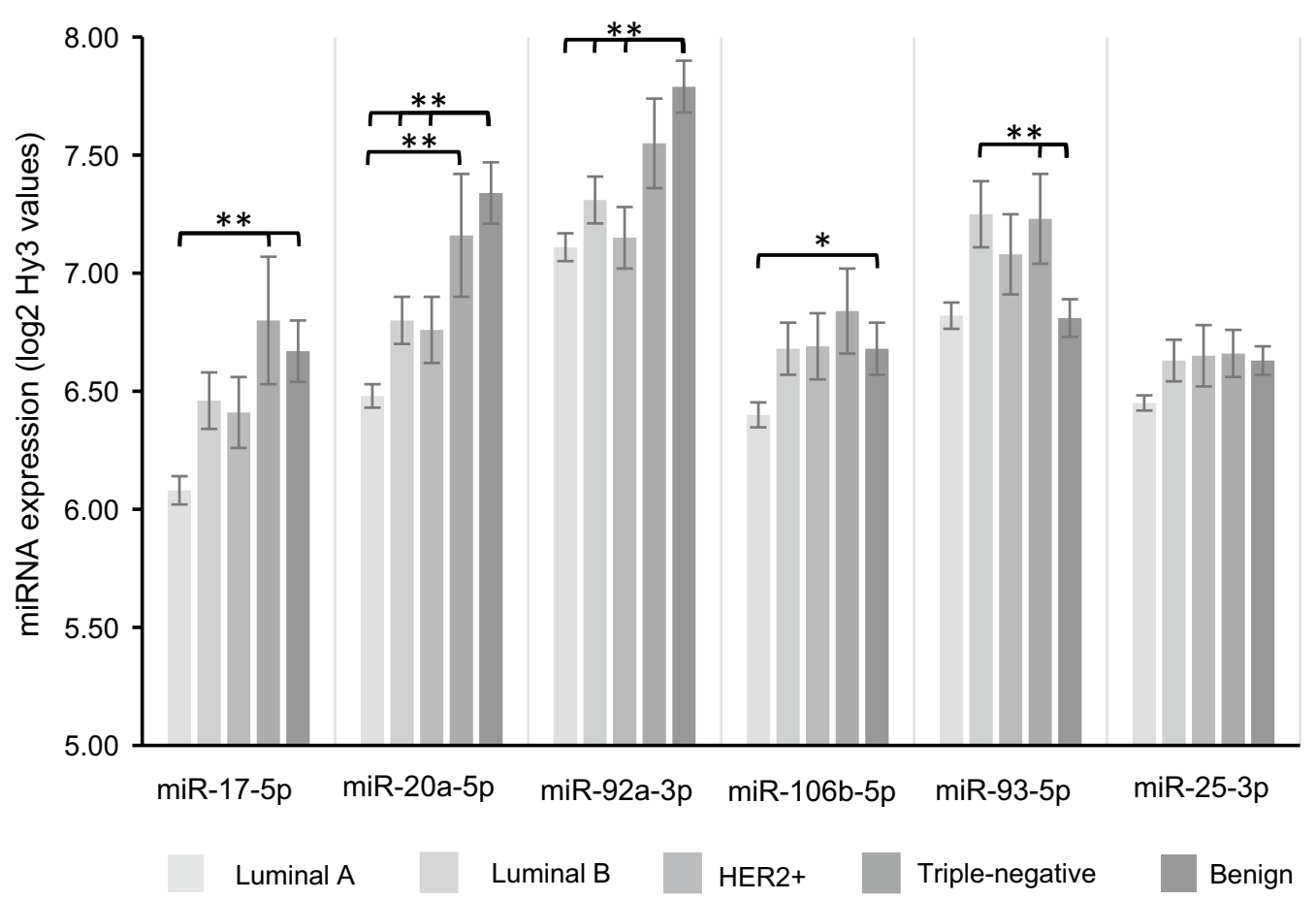

Fig. 6 Expression levels of miRNAs in the miR-17-92 and miR-106b-25 clusters according to molecular subtype. MiRNA expression in breast cancer and benign tissue is presented with microarray expression levels given as mean (standard error) of log2 transformed intensity values (Hy3). ${ }^{*}$ False discovery rate (FDR) adjusted $p$-value $<0.05,{ }^{* *} p$-value $<0.01$

one must be aware that the tissue cores contain other cellular elements contributing to the RNA pool such as immune cells, endothelial cells and fibroblasts, where malignant tissue would be expected to be more heterogenic compared to benign tissue. Hence, differences in miRNA expression between malignant and benign tissue could also, in part, be attributed to differences in tissue composition where tumor heterogeneity could influence the results [36].

Still, our results from breast cancer subgroup analyses, using both microarray and PCR, point to the miR-17-92 cluster and miR-17-family as overexpressed in aggressive breast tumors. The miR-17-92-cluster is located on chromosome 13 in the locus of the non-protein coding gene MIR17HG (miR-17-92 cluster host gene) and was first identified as the gene "chromosome 13 open reading frame 25" (C13orf25) found to be amplified in human B-cell lymphoma [37]. The cluster is transcribed as a polycistronic primary transcript that give rise to six mature miRNAs: miR-17, miR-18a, miR-19a, miR-19b, miR-20a, and miR-92a-1 [38, 39]. Transcriptional regulation of C13orf 25 can be part of the molecular basis for the coordinated expression of cluster members as observed in our study. A correlation in expression of the individual miRNAs in the miR-17-92 cluster [29] and also correlation of expression of the miR-106b-25 cluster members and their host gene $M C M 7$ on chromosome 7 has been shown [28]. The miR-17-92 cluster has been shown to be regulated by the transcription factor and proto-oncogene MYC which binds to the promoter region directly upstream of the miR-17 locus [40]. The cluster is highly expressed in a range of hematopoietic malignancies including $M Y C$-rearranged Burkitt's lymphomas [41]. High MYC-activation is also found in triple-negative breast tumors [42, 43] which could partly explain our findings of high miR-17-92-expression in triple-negative cancers. Similarly, the miR-17-92 promoter has binding sites for HES1 [39], a transcriptional repressor in the Notch signaling pathway which is overexpressed in triple-negative breast cancer [44]. N-myc has also been found to induce miR-17-92 expression in medulloblastomas [45]. NDRG2, N-myc downstream-regulated gene 2 , has been found to be significantly higher in triple-negative breast cancers compared to other subtypes [46], again indicating that differences in expression and activity of transcription factors targeting the miR-17-92 promoter vary between breast cancer subtypes and can explain differences in miR-17-92 expression.

However, we also observed significant changes in the expression of miRNAs that are members of the paralogue cluster miR-106b-25 on chromosome 7 comprising miR106b, miR-93 and miR-25. The miR-106b-25 cluster and 


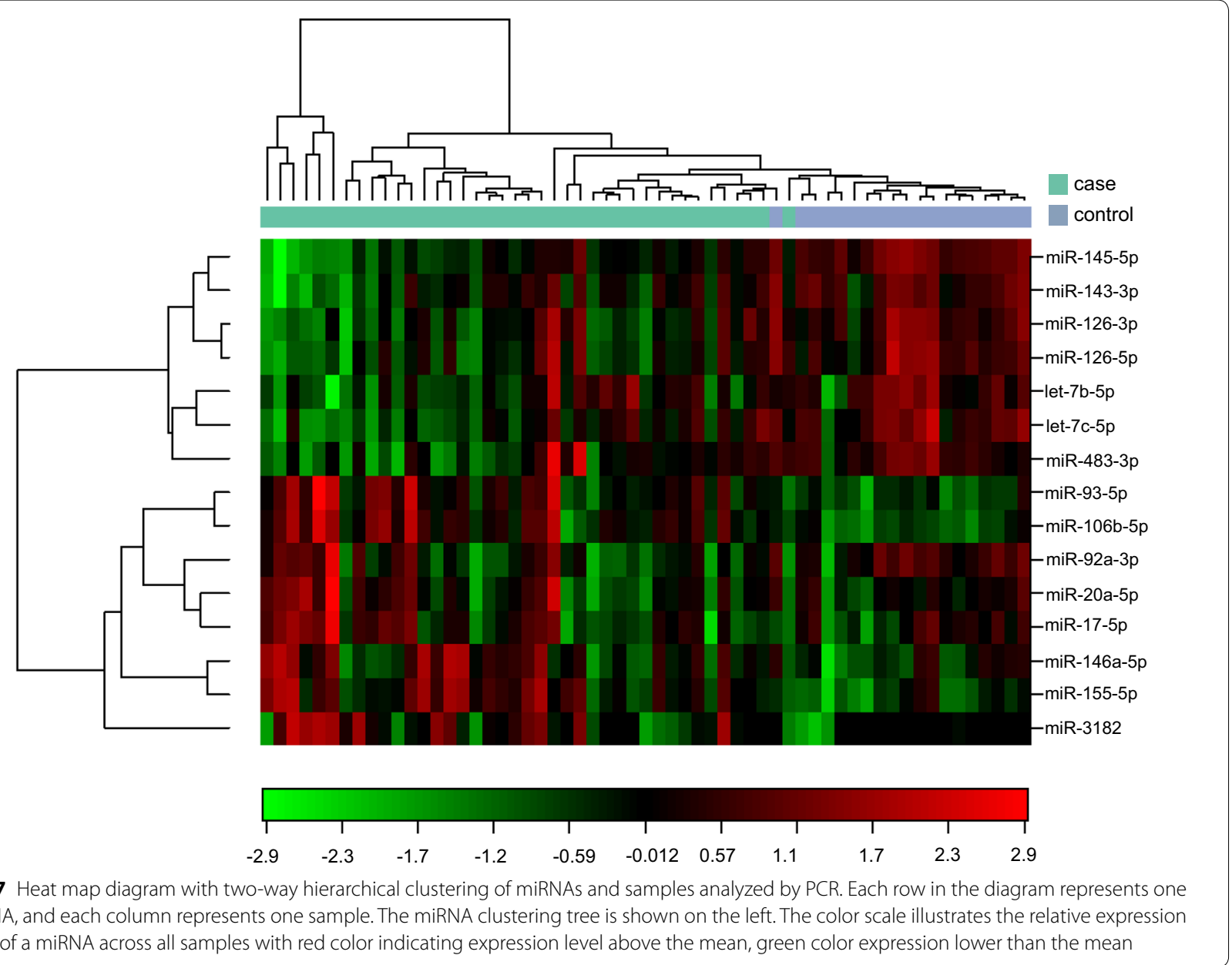

its host gene, $M C M 7$, as well as miR-20a in the miR-1792 cluster, are induced by the transcription factors E2F1 and E2F3 which are regulated by MYC [47-49]. The cluster has also been shown to be regulated by bromodomain protein 4 (BRD4) which is increased in MYC-driven cancers [50]. Similar to the miR-17-92-cluster, miR-106b-25 is transcriptionally regulated by $\mathrm{N}$-myc [51]. Of note, the expression of the miRNAs in the clusters is also regulated by mechanisms such as epigenetic modifications induced by hypoxia [52], independent transcription of pri-miRNAs from an alternative promoter, alternative splicing [53], and post-transcriptional modifications of the long primary transcripts based on their tertiary structure [54, 55]. These mechanisms allow for differential expression of the individual miRNAs within the clusters and miRNA families. Further, differences in expression of DICER1, $A G O$ and DROSHA, all crucial to miRNA biosynthesis, between breast cancer subtypes have been shown [28]. Summarized, the paralogous clusters seem to have important transcription factors and regulatory pathways in common. Indeed, it has been shown that the clusters are evolutionary conserved and it is suggested that they derive from a single gene that underwent duplication, mutations and losses of individual miRNAs [56, 57].

Further, clustered miRNAs seem to cooperate by regulating similar sets of genes belonging to specific signaling pathways [58] which fits with the sequence homology and conserved seed sequences of the miRNA within the clusters [59]. The miR-17 family of miRNAs share the same seed sequence of special importance for binding and targeting mRNAs, and include miR-17-5p, miR20a-5p, miR-20b-5p, miR-106a-5p, miR-106b-5p and miR-93-5p from clusters miR-17-92, 106b-25 and the third paralogue cluster miR-106a-363 [38]. Of the three paralogues, involving four miRNA families, the miR-1792 cluster is best described. MiR-17 and miR-19a have been shown to target mitogen activated kinases (MAPKs) such as extracellular signal-regulated kinase (ERK) $1 / 2$, and key signaling molecules in the MAPK signaling pathway such as KRAS and RAF1 [60]. The MAPK signaling pathways regulate cellular proliferation, migration, differentiation and cell death and are dysregulated 
Table 6 MiRNA expression in breast cancer and benign breast tissue, measured by PCR

\begin{tabular}{lrrrl}
\hline miRNA & $\begin{array}{l}\text { Breast cancer } \\
\text { Mean } \pm \text { SD }\end{array}$ & $\begin{array}{l}\text { Benign tissue } \\
\text { Mean } \pm \text { SD }\end{array}$ & logFC & $\boldsymbol{p}^{*}$ \\
\hline let-7b-5p & $3.41 \pm 1.11$ & $4.28 \pm 1.05$ & -0.87 & 0.0094 \\
let-7c & $2.54 \pm 0.99$ & $3.84 \pm 0.90$ & -1.30 & $4.76 \mathrm{E}-5$ \\
miR-126-3p & $2.98 \pm 1.04$ & $4.24 \pm 0.79$ & -1.26 & $5.42 \mathrm{E}-5$ \\
miR-126-5p & $-2.05 \pm 1.00$ & $-0.86 \pm 0.80$ & -1.18 & $6.19 \mathrm{E}-5$ \\
miR-143-3p & $2.84 \pm 1.16$ & $4.18 \pm 0.81$ & -1.35 & $6.19 \mathrm{E}-5$ \\
miR-145-5p & $3.31 \pm 1.53$ & $5.98 \pm 0.69$ & -2.67 & $1.79 \mathrm{E}-8$ \\
miR-155-5p & $-0.54 \pm 1.37$ & $-2.23 \pm 1.11$ & 1.69 & $5.04 \mathrm{E}-5$ \\
miR-146a-5p & $-0.48 \pm 1.36$ & $-1.22 \pm 1.08$ & 0.74 & 0.048 \\
miR-3182 & $-7.24 \pm 1.71$ & $-9.17 \pm 1.43$ & 1.93 & 0.028 \\
miR-17-5p & $-4.70 \pm 1.45$ & $-4.92 \pm 1.11$ & 0.22 & 0.60 \\
miR-20a-5p & $2.36 \pm 1.18$ & $2.29 \pm 0.67$ & 0.069 & 0.81 \\
miR-92a-3p & $1.96 \pm 1.03$ & $2.60 \pm 0.76$ & -0.65 & 0.025 \\
miR-106b-5p & $0.45 \pm 1.03$ & $-0.84 \pm 0.61$ & 1.29 & $3.81 \mathrm{E}-5$ \\
miR-93-5p & $1.76 \pm 1.03$ & $0.75 \pm 0.56$ & 1.01 & 0.00031 \\
\hline
\end{tabular}

Expression levels are presented as mean (standard deviation) of normalized PCR quantification cycle $(\mathrm{Cq})$ values based on the average of the normalizer assay detected in all samples and the formula: normalized $\mathrm{Cq}=$ average $\mathrm{Cq}$ (all samples) - assay Cq (sample). Negative PCR expression values indicate lower expression levels compared to the normalizer

* False discovery rate (FDR) adjusted $p$-value. E indicates exponential number in many cancers, including breast cancer [61]. Note that both miR-17 and miR-20a have been shown to target E2F1, thereby taking part in a negative feed-back loop where the E2F transcription factors induce transcription of miRNAs that have the same transcription factors as their target [40, 49]. In addition, miR-17 and miR-20a targets the type II transforming growth factor $\beta$ (TGF$\beta)$ receptor II whereas miR-18a targets Smad 4 downstream in the TGF- $\beta$ signaling pathway, thereby opposing the tumor-suppressive effects of TGF- $\beta$ and promoting angiogenesis [62]. Interestingly, miR-17-92 has also been found to target the cyclin-dependent kinase inhibitor p21 and the apoptosis facilitator BCL2L11 which are mediators of TGF- $\beta$ effects on proliferation and apoptosis [57]. Noteworthy, BCL2L11 is also targeted by miR-106b-25, again underlining how the miRNA clusters share targets [63]. MiR-17-5p has been shown in cellular assays to play an important role in cancer cell invasion and migration by suppressing HBP1 and consequently Wnt/ $\beta$-catenin [64]. The miR-17-92 cluster members can also suppress the specificity protein $(\mathrm{Sp})$ repressor ZBTB4, which in turn facilitates upregulation of $\mathrm{Sp}$ transcription factors and their target genes, thereby displaying tumor promoting functions [65]. MiR-19 has been shown to excert

Table 7 Expression of miRNAs in the miR-17-92 cluster and paralogues according to molecular subtype, using PCR

\begin{tabular}{|c|c|c|c|c|}
\hline MiRNA & Molecular subtype & Mean (SD) & Contrasts & $p^{*}$ \\
\hline \multirow[t]{4}{*}{ miR-17-5p } & Luminal A & $-5.49(0.73)$ & Luminal A vs others & 0.066 \\
\hline & Luminal B & $-4.93(1.43)$ & Luminal B vs others & 0.65 \\
\hline & HER2+ & $-5.03(1.70)$ & HER2 + vs others & 0.58 \\
\hline & Triple-negative & $-3.26(0.95)$ & Triple-negative vs others & 0.0025 \\
\hline \multirow[t]{4}{*}{ miR-20a-5p } & Luminal A & $1.72(0.68)$ & Luminal A vs others & 0.066 \\
\hline & Luminal B & $2.21(1.18)$ & Luminal B vs others & 0.67 \\
\hline & HER2+ & $2.15(1.19)$ & HER2+ vs others & 0.65 \\
\hline & Triple-negative & $3.45(1.03)$ & Triple-negative vs others & 0.0053 \\
\hline \multirow[t]{4}{*}{ miR-92a-3p } & Luminal A & $1.44(0.74)$ & Luminal A vs others & 0.070 \\
\hline & Luminal B & $1.75(1.00)$ & Luminal B vs others & 0.58 \\
\hline & HER $2+$ & $1.89(0.97)$ & HER2 + vs others & 0.85 \\
\hline & Triple-negative & $2.87(0.90)$ & Triple-negative vs others & 0.0073 \\
\hline \multirow[t]{4}{*}{ miR-106b-5p } & Luminal A & $-0.014(0.55)$ & Luminal A vs others & 0.12 \\
\hline & Luminal B & $0.30(1.11)$ & Luminal B vs others & 0.65 \\
\hline & HER2+ & $0.54(1.44)$ & HER2+ vs others & 0.91 \\
\hline & Triple-negative & $1.10(0.84)$ & Triple-negative vs others & 0.070 \\
\hline \multirow[t]{4}{*}{ miR-93-5p } & Luminal A & $1.20(0.73)$ & Luminal A vs others & 0.070 \\
\hline & Luminal B & $1.78(0.97)$ & Luminal B vs others & 0.93 \\
\hline & HER2+ & $1.85(1.21)$ & HER2+ vs others & 0.91 \\
\hline & Triple-negative & $2.37(1.03)$ & Triple-negative vs others & 0.085 \\
\hline
\end{tabular}

Expression levels are presented as mean (standard deviation) of normalized PCR quantification cycle (Cq) values based on the average of the normalizer assay detected in all samples and the formula: normalized $\mathrm{Cq}=$ average Cq (all samples) - assay Cq (sample). Negative PCR expression values indicate lower expression levels compared to the normalizer

* False discovery rate (FDR) adjusted $p$-value for contrast tests comparing miRNA expression levels in one molecular subtype of cancers to the other cancers grouped together. E indicates exponential number 

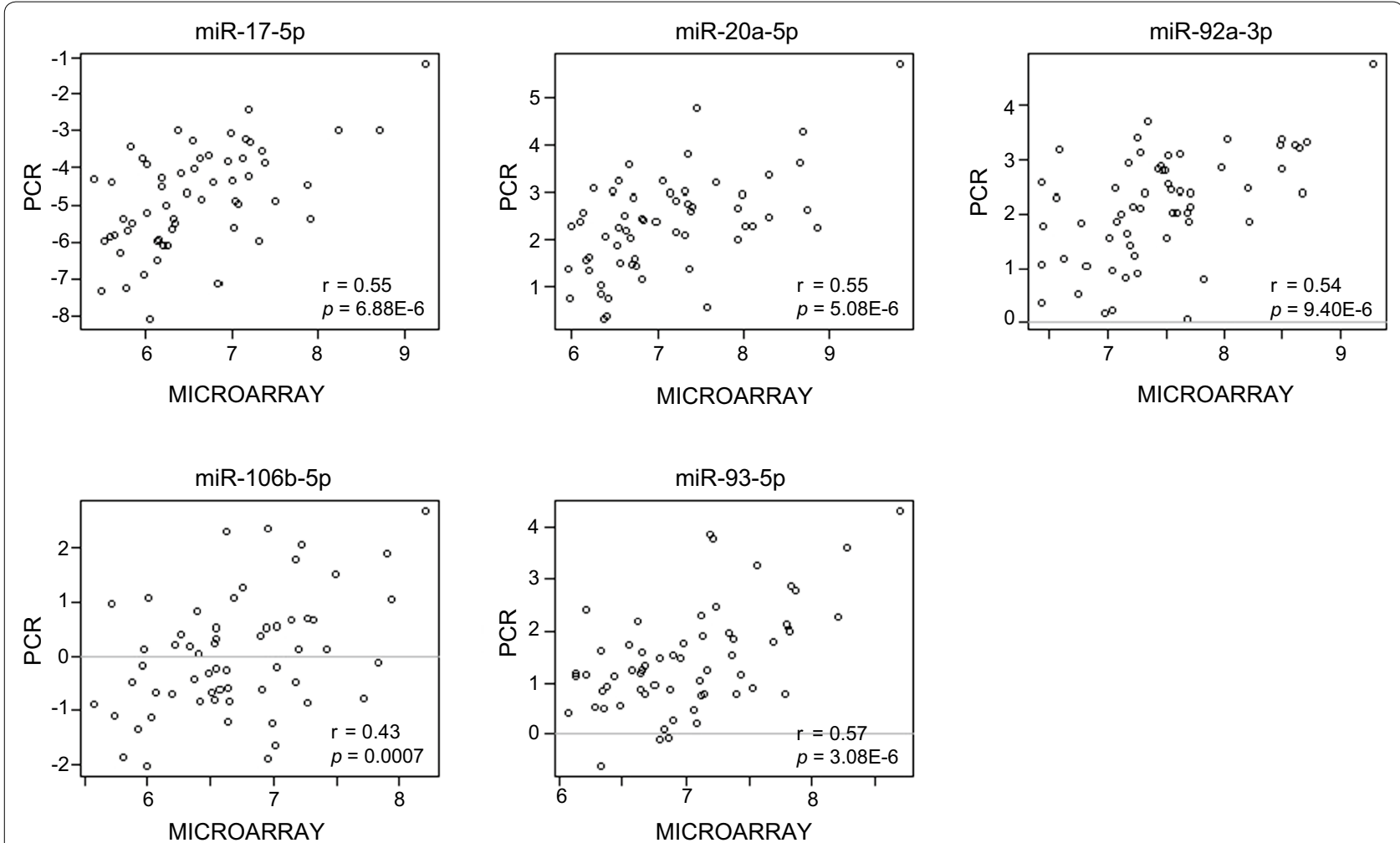

Fig. 8 Scatterplots comparing expression levels of individual miRNAs analyzed by microarray and PCR. Expression levels from microarray analyses, given as $\log 2$ transformed intensity values (Hy3), are plotted against normalized PCR expression for the different miRNAs. Pearson correlation coefficients ( $r$ ) and $p$-values are presented in the figure

oncogenic activity through binding to and repression of the tumor suppressor PTEN and activation of the AktmTOR (mammalian target of rapamycin) pathway to promote cell survival [66]. Further, the tumor suppressor p53 is a direct target of miR-25 [67]. MiR-25 has also been shown to promote proliferation in triple-negative breast cancer cells by repression of the BTG anti-proliferation factor 2 [68] whereas miR-106b has been shown to induce proliferation by targeting RB proteins in various cancers $[69,70]$. MiR-93 has been shown to increase proliferation, migration and invasion potential of MCF7 breast cancer cells and to have many potential targets involved in tumor growth, including the large tumor suppressor homologue 2 (LATS2) [33]. In summary, the miR-17-92 cluster and the miR-17 family of miRNAs have been demonstrated to regulate functions at the very core of malignancy: invasion, metastasis, cellular proliferation and resistance to apoptosis.

Microarray miRNA profiling of human breast cancer has been demonstrated to be an informative tool which can be used to classify human breast cancers [19]. However, interpretation of research data, and implementation of miRNA-profiling into clinical practice are complicated by the apparent lack of consistency between studies.
Variation in study size, design and experimental factors such as sample type, RNA quality, methods and technology platform used is challenging when trying to summarize clinically relevant data on miRNA profiling. Further, investigated miRNAs are not identical between studies. However, this study using FFPE-tissue, immunohistochemical analyses used in everyday diagnostics and a microarray with $94 \%$ coverage of human miRNAs, indicates that the miR-17-92 cluster and miR-17-family of miRNAs are of special interest in the high grade, triplenegative tumors with the worst prognosis. Further studies, including validation in an independent cohort, in situ hybridization in tissues and analyses of prediagnostic blood samples could be of interest to further evaluate the miRNA expression within tumor cells, the tumors' microenvironment and in the circulation, and the potential of these miRNAs in diagnostic pathology and clinical oncology.

\section{Conclusions}

In the NOWAC postgenome cohort, archived FFPE tissue was found suitable for miRNA analyses using microarray and PCR technology. We found the miRNA expression to be significantly different between benign 
and malignant breast tissue. When exploring the miRNA expression profiles according to receptor status, histologic grade and molecular subtypes, we found a coordinated clear upregulation of miR-17-5p, miR-20a-5p, miR-92a-3p, miR-106b-5p and miR-93-5p of the miR17-92 cluster and the miR-17-family in the most aggressive tumors with higher tumor grade and triple-negative receptor status. A validation of this pilot study in an independent cohort is a focus for future research. Further, the diagnostic and functional role of the miR-17-family of miRNAs in breast cancer should be further explored, where miRNAs' potential as markers of response to specific treatments or as biomarkers of breast cancer relapse or metastatic disease is highly interesting.

\section{Supplementary information}

Supplementary information accompanies this paper at https://doi. org/10.1186/s12967-019-2086-x.

Additional file 1: Table S1. MiRNAs demonstrating significantly different expression according to tumor size. Expression levels are given as the mean (standard deviation) of log2 transformed intensity values (Hy3) by microarray-analyses. *False discovery rate (FDR) adjusted $p$-value. $\mathrm{E}$ indicates exponential number.

\section{Abbreviations}

ER: estrogen receptor; PR: progesterone receptor; FFPE: formalin-fixed paraffinembedded; miRNA: microRNA; NOWAC: Norwegian Women and Cancer; FDR: false discovery rate.

\section{Acknowledgements}

Engineers Mona Irene Pedersen and Kristin Sorensen (UiT The Arctic University of Norway) are acknowledged for their skillful help and assistance in the laboratory with collection of study material and extraction of RNA. We are grateful to Edrun Schnell and the Cancer Registry of Norway for collecting registry data relevant for the NOWAC study.

\section{Authors' contributions}

LM was involved in planning of the study, acquisition, analyses and interpretation of the data and was the main contributor to the original draft. TB was involved in the formal analyses of data, performed the statistical analyses and contributed to the original draft, including illustrations. KAS was involved in the planning of the study and acquisition of data. EL and LTB designed and supervised the study. All authors read and approved the final manuscript.

\section{Funding}

The study was funded by the Northern Norway Regional Health Authority (Helse Nord RHF). The funder had no role in study design, data collection and analysis.

\section{Availability of data and materials}

The datasets analyzed during the current study are available from the European Genome-phenome Archive (Dataset ID: EGAD00010001406).

\section{Ethics approval and consent to participate}

The study has been approved by the regional ethical committee of North Norway (Reference Number REK Nord 2010/1931, 2013/2271). The Data Inspectorate has also approved the storing of relevant, not identifiable data and the linkage to national registries in the NOWAC study.

\section{Consent for publication}

Not applicable.

\section{Competing interests}

The authors declare that they have no competing interests.

\section{Author details}

${ }^{1}$ Institute of Medical Biology, UiT The Arctic University of Norway, Troms $\varnothing$, Norway. ${ }^{2}$ Department of Clinical Pathology, University Hospital of North Norway, Troms $\varnothing$, Norway. ${ }^{3}$ Institute of Community Medicine, UiT The Arctic University of Norway, Tromsø, Norway. ${ }^{4}$ Department of Pathology, Nordland Hospital, Bodø, Norway. ${ }^{5}$ Cancer Registry of Norway, Oslo, Norway.

Received: 27 March 2019 Accepted: 24 September 2019

Published online: 03 October 2019

\section{References}

1. International Agency for Research on Cancer. New Global Cancer Data: GLOBOCAN 2018. https://www.uicc.org/new-global-cancer-data-globo can-2018. Accessed 20 Mar 2019.

2. Cancer in Norway. Cancer incidence, mortality, survival and prevalence in Norway. Oslo: Cancer Registry of Norway; 2017. p. 2018.

3. Winter J, Jung S, Keller S, Gregory RI, Diederichs S. Many roads to maturity: microRNA biogenesis pathways and their regulation. Nat Cell Biol. 2009;11(3):228-34.

4. Hanahan D, Weinberg Robert A. Hallmarks of cancer: the next generation. Cell. 2011;144(5):646-74.

5. Jansson MD, Lund AH. MicroRNA and cancer. Mol Oncol. 2012;6(6):590-610.

6. Lu J, Getz G, Miska EA, Alvarez-Saavedra E, Lamb J, Peck D, et al. MicroRNA expression profiles classify human cancers. Nature. 2005;435(7043):834-8.

7. Cortez MA, Bueso-Ramos C, Ferdin J, Lopez-Berestein G, Sood AK, Calin GA. MicroRNAs in body fluids - the mix of hormones and biomarkers. Nat Rev Clin Oncol. 2011:8(8):467-77.

8. Weber JA, Baxter DH, Zhang S, Huang DY, Huang KH, Lee MJ, et al. The microRNA spectrum in 12 body fluids. Clin Chem. 2010;56(11):1733-41.

9. Chen $X, B a Y, M a L, C a i X$, Yin Y, Wang K, et al. Characterization of microRNAs in serum: a novel class of biomarkers for diagnosis of cancer and other diseases. Cell Res. 2008;18(10):997-1006.

10. Witwer KW. Circulating microRNA biomarker studies: pitfalls and potential solutions. Clin Chem. 2015:61(1):56-63.

11. Dumeaux V, Borresen-Dale AL, Frantzen JO, Kumle M, Kristensen VN, Lund E. Gene expression analyses in breast cancer epidemiology: the Norwegian Women and Cancer postgenome cohort study. Breast Cancer Res. 2008;10(1):R13.

12. Elston CW, Ellis IO. Pathological prognostic factors in breast cancer. I. The value of histological grade in breast cancer: experience from a large study with long-term follow-up. Histopathology. 1991;19(5):403-10.

13. Coates AS, Winer EP, Goldhirsch A, Gelber RD, Gnant M, Piccart-Gebhart $M$, et al. Tailoring therapies-improving the management of early breast cancer: St. Gallen International Expert Consensus on the Primary Therapy of Early Breast Cancer 2015. Ann Oncol. 2015;26(8):1533-46.

14. Vasconcelos I, Hussainzada A, Berger S, Fietze E, Linke J, Siedentopf F, et al. The St. Gallen surrogate classification for breast cancer subtypes successfully predicts tumor presenting features, nodal involvement, recurrence patterns and disease free survival. Breast. 2016;29:181-5.

15. Turner NC, Reis-Filho JS. Tackling the diversity of triple-negative breast cancer. Clin Cancer Res. 2013;19(23):6380-8.

16. Kreike $B$, van Kouwenhove $M$, Horlings $H$, Weigelt B, Peterse $H$, Bartelink $\mathrm{H}$, et al. Gene expression profiling and histopathological characterization of triple-negative/basal-like breast carcinomas. Breast Cancer Res. 2007;9(5):R65

17. McClintick JN, Edenberg HJ. Effects of filtering by present call on analysis of microarray experiments. BMC Bioinform. 2006;7:49.

18. Lund E, Dumeaux V, Braaten T, Hjartaker A, Engeset D, Skeie G, et al Cohort profile: the Norwegian Women and Cancer Study - NOWAC Kvinner og kreft. Int J Epidemiol. 2008;37(1):36-41.

19. Lu J, Getz G, Miska E, Alvarez-Saavedra E, Lamb J, Peck D, et al. MicroRNA expression profiles classify human cancers. Nature. 2005:435:834. 
20. Farazi TA, Horlings HM, Ten Hoeve JJ, Mihailovic A, Halfwerk H, Morozov $P$, et al. MicroRNA sequence and expression analysis in breast tumors by deep sequencing. Cancer Res. 2011;71(13):4443-53.

21. Sempere LF, Christensen M, Silahtaroglu A, Bak M, Heath CV, Schwartz $\mathrm{G}$, et al. Altered MicroRNA expression confined to specific epithelial cell subpopulations in breast cancer. Cancer Res. 2007;67(24):11612-20.

22. Iorio MV, Ferracin M, Liu CG, Veronese A, Spizzo R, Sabbioni S, et al. MicroRNA gene expression deregulation in human breast cancer. Cancer Res. 2005:65(16):7065-70.

23. Navon R, Wang H, Steinfeld I, Tsalenko A, Ben-Dor A, Yakhini Z. Novel rankbased statistical methods reveal MicroRNAs with differential expression in multiple cancer types. PLOS ONE. 2009;4(11):e8003.

24. Volinia S, Calin GA, Liu CG, Ambs S, Cimmino A, Petrocca F, et al. A microRNA expression signature of human solid tumors defines cancer gene targets. Proc Natl Acad Sci USA. 2006;103(7):2257-61.

25. Yan LX, Huang XF, Shao Q, Huang MY, Deng L, Wu QL, et al. MicroRNA miR-21 overexpression in human breast cancer is associated with advanced clinical stage, lymph node metastasis and patient poor prognosis. RNA. 2008;14:2348-60.

26. Okumura T, Shimada Y, Omura T, Hirano K, Nagata T, Tsukada K. MicroRNA profiles to predict postoperative prognosis in patients with small cell carcinoma of the esophagus. Anticancer Res. 2015;35(2):719-27.

27. Sandhu V, Bowitz Lothe IM, Labori KJ, Skrede ML, Hamfjord J, Dalsgaard $A M$, et al. Differential expression of miRNAs in pancreatobiliary type of periampullary adenocarcinoma and its associated stroma. Mol Oncol. 2016;10(2):303-16.

28. Blenkiron C, Goldstein LD, Thorne NP, Spiteri I, Chin SF, Dunning MJ, et al MicroRNA expression profiling of human breast cancer identifies new markers of tumor subtype. Genome Biol. 2007;8(10):R214

29. Lowery AJ, Miller N, Devaney A, McNeill RE, Davoren PA, Lemetre C, et al. MicroRNA signatures predict oestrogen receptor, progesterone receptor and HER2/neu receptor status in breast cancer. Breast Cancer Res. 2009;11(3):R27.

30. He YJ, Wu JZ, Ji MH, Ma T, Qiao EQ, Ma R, et al. miR-342 is associated with estrogen receptor-alpha expression and response to tamoxifen in breast cancer. Exp Ther Med. 2013;5(3):813-8.

31. Calvano Filho CM, Calvano-Mendes DC, Carvalho KC, Maciel GA, Ricci MD Torres AP, et al. Triple-negative and luminal A breast tumors: differential expression of miR-18a-5p, miR-17-5p, and miR-20a-5p. Tumour Biol. 2014;35(8):7733-41

32. Leivonen SK, Makela R, Ostling P, Kohonen P, Haapa-Paananen S, Kleivi K, et al. Protein lysate microarray analysis to identify microRNAs regulating estrogen receptor signaling in breast cancer cell lines. Oncogene. 2009;28(44):3926-36.

33. $\mathrm{Hu} J, \mathrm{Xu} J, \mathrm{Wu} Y$, Chen Q, Zheng W, Lu X, et al. Identification of microRNA-93 as a functional dysregulated miRNA in triple-negative breast cancer. Tumour Biol. 2015;36(1):251-8.

34. Avery-Kiejda KA, Braye SG, Mathe A, Forbes JF, Scott RJ. Decreased expression of key tumour suppressor microRNAs is associated with lymph node metastases in triple negative breast cancer. BMC Cancer. 2014;14:51.

35. Chang YY, Kuo WH, Hung JH, Lee CY, Lee YH, Chang YC, et al. Deregulated microRNAs in triple-negative breast cancer revealed by deep sequencing. Mol Cancer. 2015;14:36

36. Raychaudhuri M, Schuster T, Buchner T, Malinowsky K, Bronger H, Schwarz-Boeger $U$, et al. Intratumoral heterogeneity of microRNA expression in breast cancer. J Mol Diagn. 2012;14(4):376-84.

37. Ota A, Tagawa H, Karnan S, Tsuzuki S, Karpas A, Kira S, et al. Identification and characterization of a novel gene, C13orf25, as a target for 13q31-q32 amplification in malignant lymphoma. Cancer Res. 2004;64(9):3087-95.

38. Mogilyansky E, Rigoutsos I. The miR-17/92 cluster: a comprehensive update on its genomics, genetics, functions and increasingly important and numerous roles in health and disease. Cell Death Differ. 2013;20(12):1603-14.

39. Fuziwara CS, Kimura ET. Insights into Regulation of the miR-17-92 Cluster of miRNAs in Cancer. Front Med. 2015;2:64.

40. O'Donnell KA, Wentzel EA, Zeller KI, Dang CV, Mendell JT. c-Myc-regulated microRNAs modulate E2F1 expression. Nature. 2005;435(7043):839-43.

41. Tagawa H, Karube K, Tsuzuki S, Ohshima K, Seto M. Synergistic action of the microRNA-17 polycistron and Myc in aggressive cancer development. Cancer Sci. 2007;98(9):1482-90.
42. Network Cancer Genome Atlas. Comprehensive molecular portraits of human breast tumours. Nature. 2012;490(7418):61-70.

43. Chandriani S, Frengen E, Cowling VH, Pendergrass SA, Perou CM, Whitfield $\mathrm{ML}$, et al. A core MYC gene expression signature is prominent in basal-like breast cancer but only partially overlaps the core serum response. PLoS ONE. 2009;4(8):e6693

44. Li X, Cao Y, Li M, Jin F. Upregulation of HES1 promotes cell proliferation and invasion in breast cancer as a prognosis marker and therapy target via the AKT pathway and EMT process. J Cancer. 2018;9(4):757-66.

45. Northcott PA, Fernandez LA, Hagan JP, Ellison DW, Grajkowska W, Gillespie $Y$, et al. The miR-17/92 polycistron is up-regulated in sonic hedgehogdriven medulloblastomas and induced by N-myc in sonic hedgehogtreated cerebellar neural precursors. Cancer Res. 2009;69(8):3249-55.

46. Kloten V, Schlensog M, Eschenbruch J, Gasthaus J, Tiedemann J, Mijnes $J$, et al. Abundant NDRG2 expression is associated with aggressiveness and unfavorable patients' outcome in basal-like breast cancer. PLoS ONE. 2016;11(7):e0159073.

47. Petrocca F, Visone R, Onelli MR, Shah MH, Nicoloso MS, de Martino I, et al. E2F1-regulated microRNAs impair TGFbeta-dependent cell-cycle arrest and apoptosis in gastric cancer. Cancer Cell. 2008;13(3):272-86.

48. Bueno MJ, de Gomez Cedron M, Laresgoiti U, Fernandez-Piqueras J, Zubiaga AM, Malumbres M. Multiple E2F-induced microRNAs prevent replicative stress in response to mitogenic signaling. Mol Cell Biol. 2010;30(12):2983-95.

49. Sylvestre Y, De Guire V, Querido E, Mukhopadhyay UK, Bourdeau V, Major F, et al. An E2F/miR-20a autoregulatory feedback loop. J Biol Chem. 2007:282(4):2135-43.

50. Mertz JA, Conery AR, Bryant BM, Sandy P, Balasubramanian S, Mele DA, et al. Targeting MYC dependence in cancer by inhibiting BET bromodomains. Proc Natl Acad Sci USA. 2011;108(40):16669-74.

51. Shohet JM, Hicks MJ, Plon SE, Burlingame SM, Stuart S, Chen SY, et al. Minichromosome maintenance protein MCM7 is a direct target of the MYCN transcription factor in neuroblastoma. Cancer Res. 2002;62(4):1123-8.

52. Wu MZ, Cheng WC, Chen SF, Nieh S, O'Connor C, Liu CL, et al. miR-25/93 mediates hypoxia-induced immunosuppression by repressing cGAS. Nat Cell Biol. 2017;19(10):1286-96.

53. Ramalingam P, Palanichamy JK, Singh A, Das P, Bhagat M, Kassab MA, et al. Biogenesis of intronic miRNAs located in clusters by independent transcription and alternative splicing. RNA. 2014;20(1):76-87.

54. Chaulk SG, Thede GL, Kent OA, Xu Z, Gesner EM, Veldhoen RA, et al. Role of pri-miRNA tertiary structure in miR-17 92 miRNA biogenesis. RNA Biol. 2011:8(6):1105-14.

55. Chaulk SG, Xu Z, Glover MJ, Fahlman RP. MicroRNA miR-92a-1 biogenesis and mRNA targeting is modulated by a tertiary contact within the miR17 92 microRNA cluster. Nucleic Acids Res. 2014;42(8):5234-44.

56. Tanzer A, Stadler PF. Molecular evolution of a microRNA cluster. J Mol Biol. 2004:339(2):327-35

57. Ventura A, Young AG, Winslow MM, Lintault L, Meissner A, Erkeland SJ, et al. Targeted deletion reveals essential and overlapping functions of the miR-17 through 92 family of miRNA clusters. Cell. 2008;132(5):875-86.

58. Wang Y, Luo J, Zhang H, Lu J. microRNAs in the same clusters evolve to coordinately regulate functionally related genes. Mol Biol Evol. 2016:33(9):2232-47.

59. Mehlich D, Garbicz F, Wlodarski PK. The emerging roles of the polycistronic miR-106b approximately 25 cluster in cancer-a comprehensive review. Biomed Pharmacother. 2018;107:1183-95.

60. Chakraborty C, Sharma AR, Patra BC, Bhattacharya M, Sharma G, Lee SS. MicroRNAs mediated regulation of MAPK signaling pathways in chronic myeloid leukemia. Oncotarget. 2016;7(27):42683-97.

61. Dhillon AS, Hagan S, Rath O, Kolch W. MAP kinase signalling pathways in cancer. Oncogene. 2007;26(22):3279-90

62. Dews M, Fox JL, Hultine S, Sundaram P, Wang W, Liu YY, et al. The myc-miR-17 $\sim 92$ axis blunts TGF\{beta\} signaling and production of multiple TGF\{beta\}-dependent antiangiogenic factors. Cancer Res. 2010;70(20):8233-46.

63. Gupta S, Read DE, Deepti A, Cawley K, Gupta A, Oommen D, et al. Perkdependent repression of miR-106b-25 cluster is required for ER stressinduced apoptosis. Cell Death Dis. 2012;3:e333. 
64. Li H, Bian C, Liao L, Li J, Zhao RC. miR-17-5p promotes human breast cancer cell migration and invasion through suppression of HBP1. Breast Cancer Res Treat. 2011;126(3):565-75.

65. Kim K, Chadalapaka G, Lee SO, Yamada D, Sastre-Garau X, Defossez PA, et al. Identification of oncogenic microRNA-17-92/ZBTB4/specificity protein axis in breast cancer. Oncogene. 2012;31(8):1034-44.

66. Olive V, Bennett MJ, Walker JC, Ma C, Jiang I, Cordon-Cardo C, et al. miR-19 is a key oncogenic component of mir-17-92. Genes Dev. 2009:23(24):2839-49.

67. Kumar M, Lu Z, Takwi AA, Chen W, Callander NS, Ramos KS, et al. Negative regulation of the tumor suppressor p53 gene by microRNAs. Oncogene 2011;30(7):843-53.

68. Chen H, Pan H, Qian Y, Zhou W, Liu X. MiR-25-3p promotes the proliferation of triple negative breast cancer by targeting BTG2. Mol Cancer. 2018;17(1):4.
69. Samal J, Kandpal M, Vivekanandan P. HBeAg-induced miR-106b promotes cell growth by targeting the retinoblastoma gene. Sci Rep. 2017;7(1):14371.

70. Liu F, Gong J, Huang W, Wang Z, Wang M, Yang J, et al. MicroRNA-106b-5p boosts glioma tumorigensis by targeting multiple tumor suppressor genes. Oncogene. 2014;33(40):4813-22.

\section{Publisher's Note}

Springer Nature remains neutral with regard to jurisdictional claims in published maps and institutional affiliations.
Ready to submit your research? Choose BMC and benefit from:

- fast, convenient online submission

- thorough peer review by experienced researchers in your field

- rapid publication on acceptance

- support for research data, including large and complex data types

- gold Open Access which fosters wider collaboration and increased citations

- maximum visibility for your research: over $100 \mathrm{M}$ website views per year

At BMC, research is always in progress.

Learn more biomedcentral.com/submissions 